OPEN ACCESS

Edited by:

Edward S. Ruthazer,

McGill University, Canada

Reviewed by:

Ayako Wendy Ishikawa,

Keio University, Japan

Laura Baroncelli,

National Research Council (CNR), Italy

*Correspondence:

Elvire Vaucher

elvire.vaucher@umontreal.ca

Received: 11 March 2020

Accepted: 22 May 2020

Published: 03 July 2020

Citation:

Laliberté $G$, Othman $R$ and Vaucher $E$

(2020) Mesoscopic Mapping of Stimulus-Selective Response Plasticity

in the Visual Pathways Modulated by the Cholinergic System.

Front. Neural Circuits 14:38.

doi: 10.3389/fncir.2020.00038

\section{Mesoscopic Mapping of Stimulus-Selective Response Plasticity in the Visual Pathways Modulated by the Cholinergic System}

\author{
Guillaume Laliberté ${ }^{1}$, Rahmeh Othman ${ }^{1,2}$ and Elvire Vaucher ${ }^{1 *}$ \\ 'Laboratoire de Neurobiologie de la Cognition Visuelle, École d'Optométrie, Université de Montréal, Montréal, QC, Canada, \\ ${ }^{2}$ Départment de Pharmacologie et Physiologie, Faculté de Médecine, Université de Montréal, Montréal, QC, Canada
}

The cholinergic potentiation of visual conditioning enhances visual acuity and discrimination of the trained stimulus. To determine if this also induces long-term plastic changes on cortical maps and connectivity in the visual cortex and higher associative areas, mesoscopic calcium imaging was performed in head-fixed awake GCaMP6s adult mice before and after conditioning. The conditioned stimulus $\left(0.03 \mathrm{cpd}, 30^{\circ}\right.$, $100 \%$ contrast, $1 \mathrm{~Hz}$-drifting gratings) was presented 10 min daily for a week. Saline or Donepezil (DPZ, $0.3 \mathrm{mg} / \mathrm{kg}$, s.c.), a cholinesterase inhibitor that potentiates cholinergic transmission, were injected prior to each conditioning session and compared to a sham-conditioned group. Cortical maps of resting state and evoked response to the monocular presentation of conditioned or non-conditioned stimulus $\left(30^{\circ}, 50\right.$ and $75 \%$ contrast; $90^{\circ}, 50,75$, and $100 \%$ contrast) were established. Amplitude, duration, and latency of the peak response, as well as size of activation were measured in the primary visual cortex (V1), secondary visual areas (AL, A, AM, PM, LM, RL), retrosplenial cortex (RSC), and higher cortical areas. Visual stimulation increased calcium signaling in all primary and secondary visual areas, the RSC, but no other cortices. There were no significant effects of sham-conditioning or conditioning alone, but DPZ treatment during conditioning significantly decreased the integrated neuronal activity of superficial layers evoked by the conditioned stimulus in V1, AL, PM, and LM. The activity of downstream cortical areas was not changed. The size of the activated area was decreased in V1 and $\mathrm{PM}$, and the signal-to-noise ratio was decreased in AL and PM. Interestingly, signal correlation was seen only between $\mathrm{V} 1$, the ventral visual pathway, and the RSC, and was decreased by DPZ administration. The resting state activity was slightly correlated and rarely affected by treatments, except between binocular and monocular $\mathrm{V} 1$ in both hemispheres. In conclusion, cholinergic potentiation of visual conditioning induced change in visual processing in the superficial cortical layers. This effect might be a key mechanism in the establishment of the fine cortical tuning in response to the conditioned visual stimulus.

Keywords: cholinergic potentiation, mesoscale calcium imaging, visual conditioning, acetylcholinesterase inhibitors, visual cortex 


\section{INTRODUCTION}

Vision is a primary sense that drives one's assessment of the external world and guides behavioral responses. Visual perception results from an interplay between various cortical areas. These areas are hierarchically organized, starting in the primary visual cortex (V1) (Glickfeld and Olsen, 2017). In mice, 12 associative visual areas, sharing close anatomical, and functional relationships with V1 (Wang and Burkhalter, 2007), process the information of complex visual stimuli. This processing starts with very selective responses of visual neurons for specific parameters of stimuli, such as orientation, spatial and temporal frequencies, and direction, which are associated with the visual hierarchy (Andermann et al., 2011). The functional selectivity of neurons and cortical areas defines visual pathways that follow a dorsal and a ventral stream in mice, as observed in greater mammals (Mishkin et al., 1982; Glickfeld et al., 2013a). The examination of circuitry between visual areas has revealed that the murine dorsal pathway, which sustains spatial perception, is composed of the latero-medial area (LM), laterointermediate area (LI), posterior area $(\mathrm{P})$, and postrhinal area (Por) (Figure 1). The ventral pathway, which allows for the recognition of stimulus attributes, consists of the anterolateral area $(\mathrm{AL})$, anterior area $(\mathrm{A})$, anteromedial area $(\mathrm{AM})$, rostrolateral area (RL), and posteriomedial area (PM) (Huberman and Niell, 2011; Wang et al., 2012). The dense projections from $\mathrm{V} 1$ to the $\mathrm{LM}$ and $\mathrm{AL}$ areas suggest that these areas could represent the entries of the dorsal and ventral visual pathways in mice, respectively.

The extraction of important visual information from the external environment requires neurons to respond with a differential strength and, consequently, involve specific visual microcircuits. A specific stimulus might require a high level of processing, thanks to neuronal gain modulation (Soma et al., 2012, 2013a) and neuronal plasticity, which would result in the persistent change of the neuronal response to this stimulus, as well as structural changes. Neuronal plasticity is defined as the principle of learning and the permanent improvement of perception. It is highly expressed in the developing brain, but it is rather latent after brain maturation when plasticity brakes such as Lynx1 (Morishita et al., 2010) are upregulated, or during the perineuronal net development (Hensch, 2005). Plasticity has to be reactivated in adults, specifically by manipulating the excitatory-inhibitory cortical balance via neuromodulation or by eliciting the long-term potentiation of the synapse strength. Also, neuronal plasticity could be reactivated via expression of plasticity factors that enhance plasticity, e.g., Lypd6 (Darvas et al., 2009; Sadahiro et al., 2016), or that structurize neuronal connectivity, such as the tissue plasminogen protein $\mathrm{tPa}$ (Mataga et al., 2002), and the synaptic proteins GAP43 (Han et al., 2013) or PSD95 (Kim and Sheng, 2004).

Stimulus-specific response plasticity is induced by conditioning in which a repetition of the stimulus enables the consolidation of neuronal reactivity. In the visual pathway, stimulus-specific response potentiation in V1 has been shown to involve gamma oscillations, the GABAergic microcircuits, and long-term potentiation of the response according to an
Hebbian pattern (Cooke and Bear, 2010; Chen N. et al., 2012). It has also been shown to be enhanced by the cholinergic system (Kilgard and Merzenich, 1998; Rokem and Silver, 2013; Chen et al., 2015; Galuske et al., 2019; Vaucher et al., 2019), which strongly interacts with both the cortical GABAergic and glutamatergic microcircuits, inducing long-term potentiationlike mechanisms and refining circuitry efficiency. For these reasons, the cholinergic system has been proposed to be a key player in experience-induced plasticity. Acetylcholine $(\mathrm{ACh})$ modulates the inhibitory GABAergic response through cholinergic nicotinic and muscarinic receptors (Mcclure-Begley et al., 2009; Disney et al., 2012; Demars and Morishita, 2014; Groleau et al., 2015). Additionally, ACh has multiple effects on the visual response, including effects on the latency (Turchi and Sarter, 1997), spread (Kimura et al., 1999; Voss et al., 2016), and signal gain (Minces et al., 2017) of the cortical response. From a behavioral point of view, it has been demonstrated that this neuromodulator enhances visual acuity (Kang et al., 2014) and recognition (Chubykin et al., 2013; Gavornik and Bear, 2014), as well as contrast detectability (Bhattacharyya et al., 2013; Soma et al., 2013c). These changes were measured in layer 4 of V1, or MT (Chen X. et al., 2012) in rodents and primates, and in associative areas. Notably, donepezil (DPZ, a cholinesterase inhibitor that potentiates cholinergic transmission) administration was found to reduce functional connectivity between cortical areas of the visual hierarchy in order to favor automated processing (Ricciardi et al., 2013). The cholinergic system controls cortical processing in defined cortical areas, though it can also coordinate cortical function as the cholinergic input comes from the basal forebrain. This cholinergic system sends wide but organized projections to the cortical mantle (Gaykema et al., 1990; Coppola et al., 2016; Huppé-Gourgues et al., 2018).

In the present study, the regional distribution of the effects of visual conditioning and DPZ was investigated in awake head-fixed Thy1-GCaMP6s mice. The goal of the study was to evaluate whether the cholinergic system would change the correlation of neural activity between areas to enhance efficiency and automation of the processing of the trained stimulus. The cholinergic system was potentiated through systemic administration of $0.3 \mathrm{mg} / \mathrm{kg}$ DPZ (Bontempi et al., 2003; Geerts et al., 2005; Bretin et al., 2018). A monocular conditioning to an oblique pattern was performed daily for a week. We used mesoscale calcium imaging (mCaI), which assesses the calcium influx from the excitatory (expressing Thy-1) neurons bodies and neurites of the superficial cortical layers (Chen et al., 2013; Dana et al., 2014), and allows for the establishment of whole-brain cortical maps. The focus was placed on the most reactive cortical areas, particularly V1, in both hemispheres, contralateral and ipsilateral to the stimulation ( $\mathrm{cV} 1$ and $\mathrm{iV} 1)$, as well as five areas of the ventral pathway (AL, A, AM, RL, and $\mathrm{PM}$ ) that show great tuning for oriented gratings (Smith et al., 2017), and one area of the dorsal pathway (LM). The activity of the retrosplenial cortex (RSC) was assessed because of its role in contextual learning and memory (Makino and Komiyama, 2015; Leaderbrand et al., 2016). High-level areas were also analyzed but not reported as the signal was not significantly 


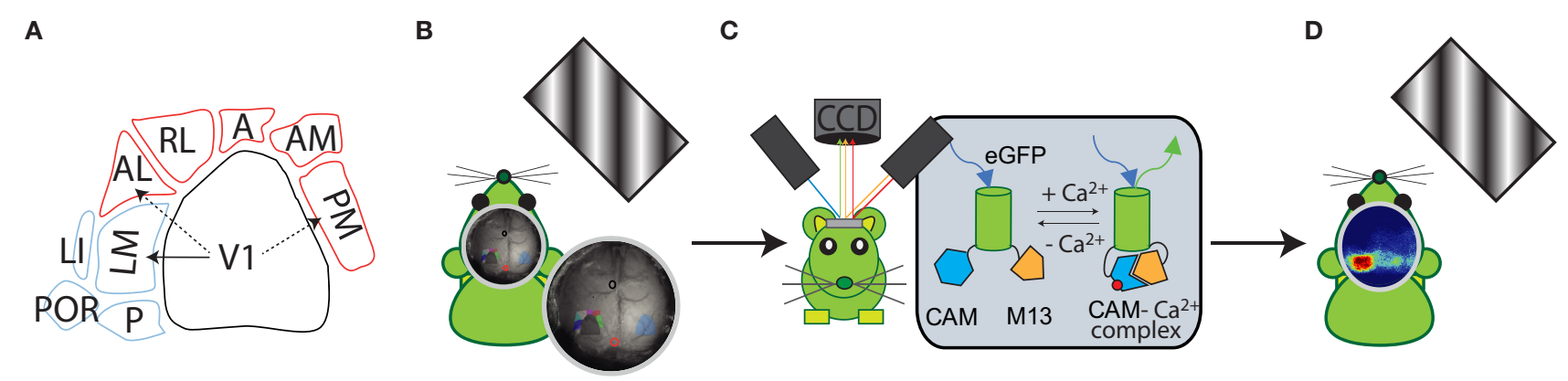

E

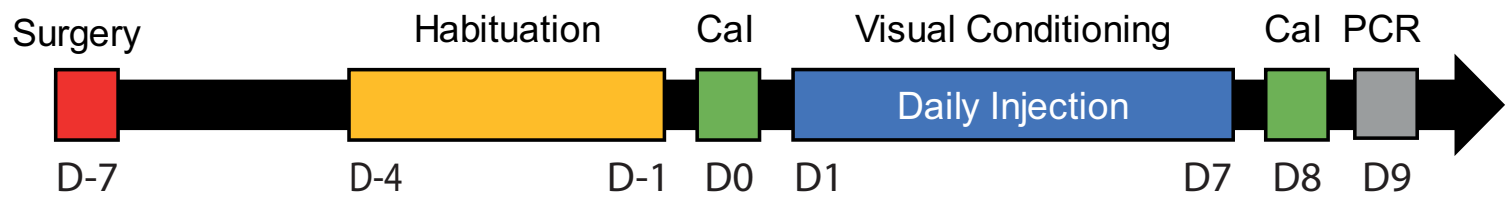

$\mathbf{F}$

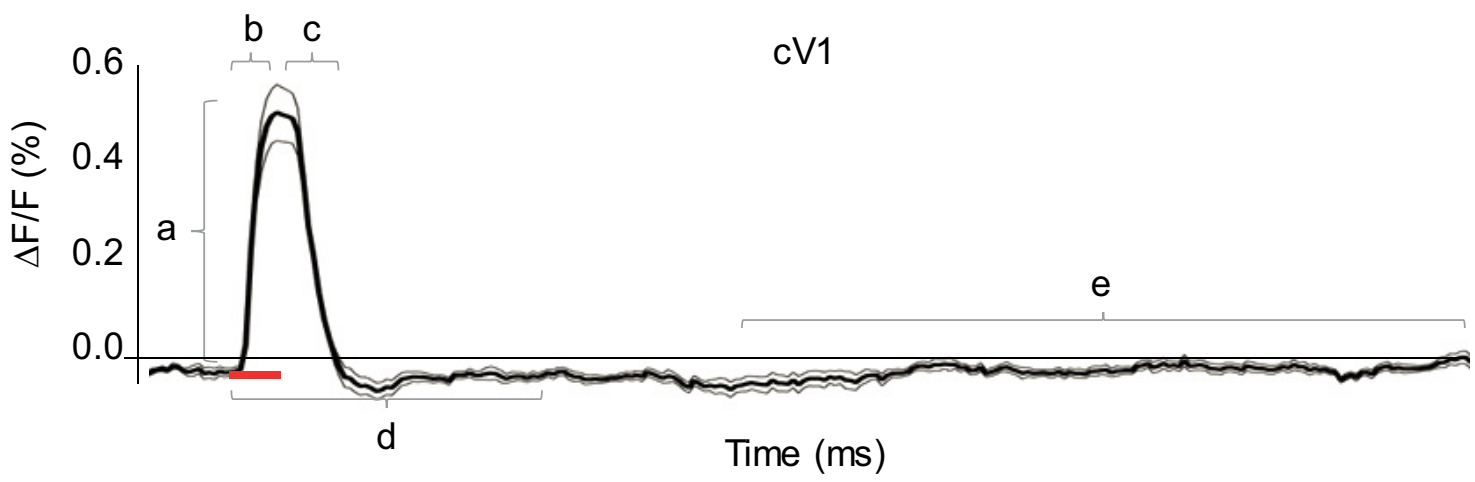

G

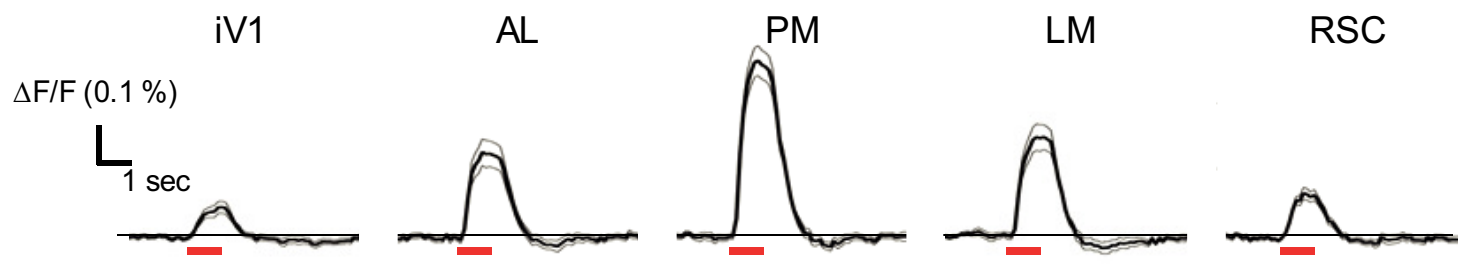

FIGURE 1 | Visual pathways and methodology. (A) Schematic representation of the visual cortical areas adapted from (Zhuang et al., 2017) and their belonging to the dorsal (purple) or ventral (blue) stream. The density of V1's projections to LM, AL, and PM are greater (arrows) in these areas compared to adjacent areas, suggesting that $\mathrm{LM}$ and $\mathrm{AL}$ are the gateway for each visual stream. (B) Schematic representation of the experimental set-up: a monitor was placed on the right side $\left(120^{\circ}\right)$ of the head-fixed mouse to monocularly stimulate the right visual field by drifting oriented gratings. (C) A CCD camera was placed dorsal to the mouse skull to acquire light absorbance and fluorescent signal fluctuations in the cortex through an optic chamber. During the acquisition, the brain of the mouse was sequentially illuminated by three LED lights (see text for details). (D) Representation of cortical map in response to the monocular visual stimulation. (E) Timeline for the mice treatment and experimentation (mCal, mesoscale Calcium Imaging; V.C., Visual Conditioning; RT-qPCR, retro-transcription quantitative polymerase chain reaction). (F) Trace of the mean CaS in function of time ( $n=18$ mice; 15 repetitions each, mean in dark, \pm SEM in gray) in response to the $30 \mathrm{H}$ visual stimulation (represented by a red bar) in cV1. Representation of the parameters examined is shown: Amplitude (a), Latency (b), Persistence (c), Activation correlation window (d) and the baseline (e).

(G) Traces of the CaS mean response to the visual stimulation (red bar) in function of time ( $n=18$ mice; 15 repetitions each, mean in dark, \pm SEM in gray), during the time window used for activation correlation calculation in iV1, AL, PM, LM, and RSC. CV1, contralateral primary visual cortex; iV1, ipsilateral primary visual cortex; PM, posterior-median cortex; LM, latero-median cortex; A, anterior cortex; AL, anterio-lateral cortex; AM, anterio-median cortex; RL: rostro-lateral cortex; RSC,

retrosplenial cortex. 
affected by the visual stimulation. Different parameters of the fluorescent calcium signal (CaS, representing $\Delta \mathrm{F} / \mathrm{F}, \%)$ were measured: the amplitude, the size of the activated area, the signal-to-noise ratio ( $S N R)$, the latency, and the persistence of the maximal signal, which is indicative of the strength, rapidity and efficiency of the neural processing. The resting state functional connectivity was calculated before and after visual conditioning to assess the reorganization of circuitry efficiency. Finally, to investigate through which plasticity mechanisms the cholinergic enhancement and conditioning affect the visual cortex, the expression of Lypd6, Lynx1, tPa, GAP43, and PSD95 were examined by RT-qPCR after treatments.

\section{MATERIALS AND METHODS}

\section{Mice}

All procedures were approved by the Animal Care Committee of the University of Montreal (CDEA, protocol 19-024) and conformed to the guidelines of the Canadian Council on Animal Care. Transgenic heterozygous GCaMP6s mice ( $n$ $=18,9$ males and 9 females equally distributed in three groups) were produced in our colony by breeding C57BL/6JTg(Thy1-GCaMP6s)GP4.3Dkim/J (IMSR Cat\# JAX:024275, RRID:IMSR_JAX:024275) males with C57BL/6J wild type (IMSR Cat\# JAX:000664, RRID:IMSR_JAX:000664) females, in agreement with the university's reproduction protocol (CDEA, 19-025). The GCaMP6s expression was determined by genotyping each animal with PCR amplification, in accordance with the Jackson Laboratory (RRID:SCR_004633) procedures for this strain. Mice were kept in a 12 h-light cycle room with ad libitum access to food and water. To prevent any potential bias caused by the circadian cycle, daily experiments (habituation, $\mathrm{mCaI}$ acquisition, drugs administration, and visual conditioning) were performed within the same daily time period (between 8 and 12 AM) for each mouse. The testing order was randomly determined on the first day using one mouse from each experimental group [non-conditioned group [Sham], control conditioned [CS], or $0.3 \mathrm{mg} / \mathrm{kg} \mathrm{DPZ}$ conditioned [CS/DPZ] group; six series of experiments were performed]. Three (one in each group) out of the 18 initial mice were removed after complications following the surgery or during the treatment, thus there were $n=5$ per group.

\section{Surgical Procedures}

For chronic implantation of the imaging chamber, animals were anesthetized with isoflurane (induction at 5\%, maintain in $1.5 \%$; in medical $\mathrm{O}_{2}$ ) and placed in a stereotaxic frame. Body temperature was maintained at $37^{\circ} \mathrm{C}$ using a heating pad and monitored with a rectal thermometer throughout the procedure. The scalp was shaved, decontaminated with ethanol (70\% v/v) and iodine $(16 \% \mathrm{v} / \mathrm{v})$, and locally anesthetized with subcutaneous injection of lidocaine $(32 \mathrm{mg} / \mathrm{kg})$. The skin covering the skull was removed and replaced with transparent dental cement $(C \& B$ MetaBond, Parkell, Edgewood, NY, USA), a cover glass (Carolina, Burlington, NC, USA), and an $11 \mathrm{~mm}$ diameter titanium head fixation chamber. At the end of the procedure, mice were injected subcutaneously with a non-steroidal anti-inflammatory drug, carprofen $(0.5 \mathrm{mg} / \mathrm{kg})$, in saline (injection volume equivalent to a ratio of $0.1 \mathrm{~mL} / 10 \mathrm{~g}$ of the mouse's weight) solution and allowed to recover for $30 \mathrm{~min}$ in a red-light warmed cage. They were then placed individually in a clean cage. A second and third subcutaneous injection of carprofen $(0.5 \mathrm{mg} / \mathrm{kg})$ were performed at 24 and $48 \mathrm{~h}$ after the surgery. The animal was allowed to recover 5 days after the surgery before beginning any headfixed procedure.

\section{Mesoscale Calcium Imaging Recordings}

The fluorescent CaS recording was performed on awake headfixed mice at day 0 (D0, before the conditioning) and day 8 (D8, 1 day after conditioning) (Figure 1). No recording of the $\mathrm{CaS}$ in response to a visual stimulation was performed during conditioning (7 consecutive days). For the resting state cortical activity, the CaS was acquired at D0 and D8 during a period of 10 min prior to visual stimulation.

During $\mathrm{mCaI}$ acquisition, the mice stand inside a fenestrated PVC tube on a height-adjustable stage placed within a dark cabinet. A computer monitor $\left(60 \mathrm{~Hz}\right.$ refresh time; $250 \mathrm{~cd} / \mathrm{m}^{2}$, main luminance) was positioned at $21 \mathrm{~cm}$ from the mouse's side $\left(120^{\circ}\right)$ to stimulate its entire monocular visual field (Figure 1B). To minimize stress, mice were progressively habituated to the head-fixation apparatus over 5 days: 5, 10, 20, and $40 \mathrm{~min}$ head fixation periods without brain illumination for the first 4 days, respectively, and then $40 \mathrm{~min}$ with brain illumination and gray screen presentation for the last day of habituation. This habituation abolished signs of stress in the cage and on the stage (mice showed adequate grooming, diminution of vocalization, diminution of movements during the head fixation, and no weight loss). The mice were placed in a dark room for $30 \mathrm{~min}$ prior any $\mathrm{CaI}$ recording including $5 \mathrm{~min}$ head-fixation at rest. The CaI recording was synchronized to the visual stimulation with the Datapixx3 device (Vpixx Technologies Inc., St Bruno, QC, Canada).

The CaS was recorded through a CCD camera (NIKKOR $50 \mathrm{~mm}$ f/1.2, Nikon, Minato, Tokyo, Japan) positioned vertically above the skull (Figure 1C). A dark opaque screen was placed between the monitor displaying the visual stimulation and the imaging chamber/camera to ensure there was no light contamination. Sequential 472, 590, and $623 \mathrm{~nm}$ brain illumination was produced by three LEDs contained in two adjustable illumination arms (Figure 1C) directly on the skull of the mouse. Calcium indicators were excited at $472 \mathrm{~nm}$ (Blue LED, Cree XLamp XP-E2 LEDs, Cree, Durhamm, NC, USA) and intrinsic signals (absorbance of oxy- and deoxy- hemoglobin) were extracted from modifications in the absorption of the 590 and $623 \mathrm{~nm}$ wavelengths (Amber LED, LZ4-00MA00 and Red LED, LZ4-00MA00, respectively, OSRAM, Markham, Ontario, Canada). The reflectance of intrinsic signals and the fluorescence emission were collected at a frame rate of $30 \mathrm{~Hz}(10 \mathrm{~Hz}$ by wavelength) with a full resolution of $512 \times 512$ pixels $(21.5$ $\mu \mathrm{m} /$ pixel). Illumination was adjusted to avoid under or over saturation of any wavelengths. The exposure time of the camera was set to $18 \mathrm{~ms}$. Filters (long pass filter at $496 \mathrm{~nm}$ adjusted to the objective) were used to minimize any contamination from other wavelengths. 


\section{Image Processing and Analysis of Calcium Signals}

All data were imported and analyzed with Labeo Technologies, Inc. and MATLAB codes (MathWorks, Natick, MA, USA, RRID:SCR_001622). Prior to data analysis, recorded images of the whole cortex were corrected for the camera's electronic noise. In addition, each pixel's intensity time course was filtered with a low pass filter to remove high frequency artifacts related to respiration and heart rate. Pixels were fused 1:2, so CaI analysis was performed over a $256 \times 256$ pixel window ( $43 \mu \mathrm{m} /$ pixels $)$. Tissue absorbance due to the hemodynamic response (assessed by the at 590 and $623 \mathrm{~nm}$ illumination) was subtracted from the fluorescence signal using a modified Beer-Lambert equation (Guevara et al., 2013). The corrected $\mathrm{CaS}(\Delta \mathrm{F} / \mathrm{F}, \%)$ of each pixel was normalized by subtracting the current $\mathrm{CaS}$ with the $\mathrm{CaS}$ baseline over the $\mathrm{CaS}$ baseline $\times 100$. The $\mathrm{CaS}$ of each pixel $\left(\mathrm{CaS}_{\mathrm{p}}\right)$ was then spatially normalized using the $\mathrm{Z}$-score to create cortical activity maps (Gias et al., 2005) (Figures 1D, 2).

$$
Z-\text { score }=\frac{C a S_{p}-\operatorname{mean}\left(C a S_{p}\right)}{S D\left(C a S_{p}\right)}
$$

The size and position of the regions of interest (ROIs) were adapted from the Allen Brain Institute (Zhuang et al., 2017) and other anatomical and functional studies imaging the mouse visual cortex (Andermann et al., 2011; Marshel et al., 2011; Wang et al., 2012; Glickfeld et al., 2013a; Groleau et al., 2014; Wekselblatt et al., 2016). A ROI template was generated, manually centered, and fitted to Bregma and Lambda (Figures 1B, 2B). The size and position of the ROIs were automatically corrected according to the Bregma and Lamda distance for each mouse at D0 to avoid misidentification and cross-contamination between secondary visual areas. The $\mathrm{CaS}$ of each pixel contained in the ROIs was averaged in response to each visual stimulation (15 times). The resultant ROIs' CaS was then averaged across animals $(n=18)$. The CaS response in a particular ROI was considered an outlier and removed from the analysis when the CaS simultaneously measured in control areas (primary motor and somatosensory cortex) varied from the mean CaS calculated across the whole cortex (calculated with a $95 \%$ confidence interval).

Various stimulation parameters were calculated (Figure 1F):

The Amplitude was calculated by subtracting the baseline recorded during gray screen presentation from the maximal fluorescent signal during the stimulus presentation.

$$
\text { Amplitude }=\mathrm{CaS}_{\mathrm{Max}}-\mathrm{CaS}_{\text {Baseline }}
$$

The Size was defined as the surface (number of pixels) of each ROI activated by the visual stimulation. We considered that the ROI was activated when the z-score of the pixel's CaSmax was $>1.282$. The number of activated pixels was normalized by the surface of the ROI to minimize the impact of the ROI dimensions.

$$
\text { Size }=\frac{\text { Pixels }_{Z-\text { score }}>1.282}{\text { Pixels } \text { Total in } R O I}
$$

The Latency represented the time interval from the beginning of the visual presentation to $\mathrm{CaS}_{\mathrm{Max}}$.
The Persistence was the time interval between the end of the stimulation presentation and the end of the CaS, i.e., when the fluorescent signal corresponded to $<2 \mathrm{SD}$ of the baseline.

$$
\text { Persistence }(m s) \rightarrow C a S \leq\left(\text { CaS } \text { Baseline }+2 \sigma_{\text {Baseline }}\right)
$$

The signal-noise ratio (SNR) of local activation was calculated by measuring the ratio between the maximal response for the stimulation and the standard deviation of the signal baseline.

$$
S N R=\frac{\left(\text { CaS }_{\text {Max }}\right)}{\sigma_{\text {Baseline }}}
$$

The activation correlation between the nine ROIs was determined using the MATLAB function corrcoef over a $40 \mathrm{~ms}$ window starting at the beginning of the stimulus presentation and represented by a matrix.

The resting state correlation was determined by measuring the cross-correlation coefficient $r$ values between the temporal profiles of each of the 11 seed pixels (LM, V1b, V1m, AL, $\mathrm{PM}, \mathrm{RL}, \mathrm{A}, \mathrm{AM}, \mathrm{RSC}, \mathrm{AC}$, and $\mathrm{M} 1$ where $\mathrm{AC}$ and $\mathrm{M} 1$ are the anterior cingulate cortex and primary motor cortex, respectively) in each hemisphere (and all others over $10 \mathrm{~min}$ of resting state acquisition). Their locations were defined according to the Allen Institute Atlas (Allen Reference AtlasMouse Brain, RRID:SCR_013286) and were corrected by the distance between the manually selected Bregma and Lambda as previously described.

\section{Visual Stimulation}

The visual stimulation provided during $\mathrm{CaI}$ acquisition consisted of a series of drifting gratings (spatial frequency: $0.03 \mathrm{cpd}$, temporal frequency: $1 \mathrm{~Hz}$, orientation: 30 or $90^{\circ}$, contrast: 50,75 , or $100 \%$ ) produced by a Vpixx software (Vpixx Technologies Inc.) and displayed on an LCD screen (23" ACER LCD monitor S230HL, Refresh Rate $60 \mathrm{~Hz}$, Brightness $250 \mathrm{~cd} / \mathrm{m}^{2}$ ) positioned in the right monocular field at $21 \mathrm{~cm}$ from the mice (Figure 1B). Each stimulus was randomly presented 15 times during $1 \mathrm{~s}$ with $25 \mathrm{~s}$ of inter-stimulation intervals (gray screen). The CaS parameters were calculated for each distinct visual stimulation condition.

\section{Visual Conditioning}

The visual conditioning of awake head-fixed mice consisted of a unilateral left exposure to a specific stimulus every day over 7 consecutive days (Figure 1E). A unilateral presentation of a gray screen was used for the non-conditioned group, while a drifting grating (S.F.: 0.03 cpd, T.F.: $1 \mathrm{~Hz}$, Ori.: $30^{\circ}$, Con.: 100\%) was presented to both conditioned groups during $50 \mathrm{~s}$ for 12 presentations with $10 \mathrm{~s}$ intervals of presentation (for a total stimulation time of $10 \mathrm{~min}$ ).

\section{Drug Administration}

Mice were injected subcutaneously behind the neck with 0.1 $\mathrm{mL} / 10 \mathrm{~g}$ (mouse weight) of sterile saline (Sham and CS, $n=5$ per group) or with $0.3 \mathrm{mg} / \mathrm{kg} \mathrm{DPZ} \mathrm{(Bontempi} \mathrm{et} \mathrm{al.,} \mathrm{2003;} \mathrm{Bretin}$ et al., 2018) diluted in $0.1 \mathrm{~mL} / 10 \mathrm{~g}$ (mouse weight) of sterile saline (CS/DPZ; $n=5$ ) $15 \mathrm{~min}$ prior to the visual conditioning 

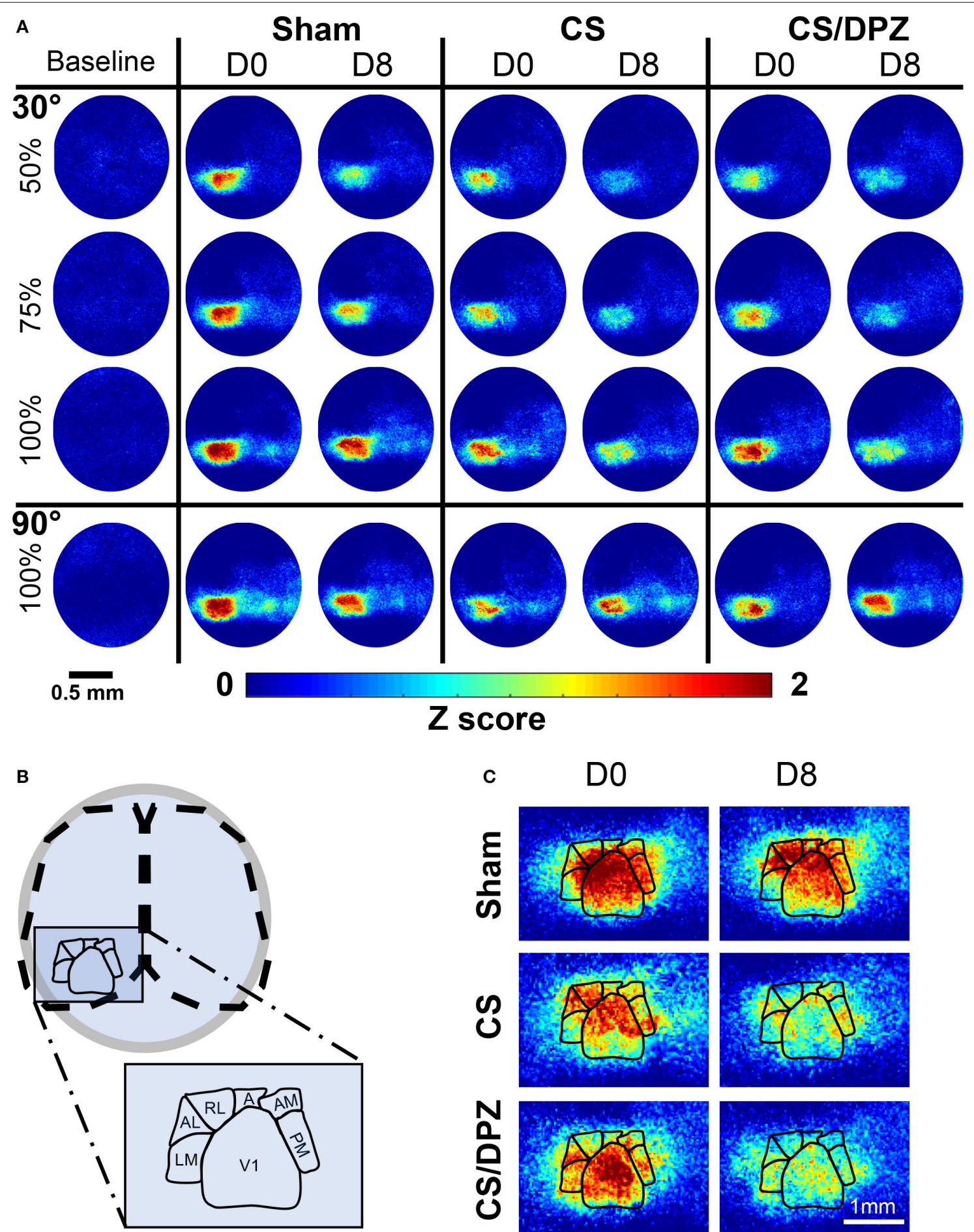

D8

FIGURE 2 | Cortical activation maps of adult Thy1-GCaMP6s mice. (A) Color-coded maps show the effect of a sham-conditioning (Sham) visual conditioning coupled with saline (CS) or cholinergic potentiation (CS/DPZ) on the cortical response in superficial layers. Response to a conditioned oriented visual stimulation in different contrast (30 L, 50\%, $30 \mathrm{M}, 75 \%$, and $30 \mathrm{H}, 100 \%$, top panel) and a non-conditioned orientation (90 H, 100\%, bottom panel) are represented at day 0 (D0) and day8 (D8) after the conditioning. The cortical response to the conditioned stimulus and its lower contrast- equivalent is reduced for both injection groups (Data represented in $z$-score median, $n=5$ /experimental groups). (B) Schematic representation of the ROI mask used to extract CaS from the different visual cortices. (C) Magnification of the visual areas (for the $30 \mathrm{H}$ stimulation). The reduction of cortical response has a general occurrence across the visual areas, while the ventral stream (AL, $R L$, $A$, $\mathrm{AM}$, and PM) express more initial (DO) activation than the dorsal path (LM) for the visual stimulation. 
TABLE 1 | Primers list.

\begin{tabular}{lll}
\hline & & \multicolumn{2}{l}{ Sequence } \\
\hline GCaMP6s & Forward & 5'-ACA AGC AGA AGA ACG GCA TC-3' \\
& Reverse & 5'-TGG TAG TGG TAG GCG AGC TG-3' \\
18S & Forward & 5'-GTA ACC CGT TGA ACC CCA TT-3' \\
& Reverse & 5'-CCA TCC AAT CGG TAG TAG CG-3' \\
Lynx1 & Forward & 5'-CCA CCT ACT GTA TGA CCA CAC G-3' \\
& Reverse & 5'-CAA CAG CAG GTG GCA GAT GCA T-3' \\
Lypd6 & Forward & 5'-CAC TCC GTA TCC TGG TGG GTT T-3' \\
& Reverse & 5'-GAC TTC CAT CGT GTG CTG AGT G-3' \\
tPa & Forward & 5'-TGG TGC TGT TGG TAA GTT GT-3' \\
& Reverse & 5'-TGC CTG ACC AGG GAA TAC AT-3' \\
PSD95 & Forward & 5'-TCA ACA CGG ACA CCC TAG AA-3' \\
& Reverse & 5'-TGA GTT ACC CCT TTC CAA TG-3' \\
GAP43 & Forward & 5'-TGG AAC AAG ATG GTG TCA AG-3' \\
& Reverse & 5'-CCT TTG AGC TT TTC CTT GT-3' \\
M2 & Forward & 5'-AAG TCA ACC GCC ACC TTC AGA C-3' \\
& Reverse & 5' GTA GCC AAT CAC AGT GTA GAG GG-3'
\end{tabular}

session in order to reach the maximal cortical effect of the drug (Geerts et al., 2005).

\section{RNA Extraction}

Immediately after the last CaI session, mice were deeply anesthetized with pentobarbital and sacrificed by decapitation. The brain was collected on a cold plate and placed in RNAlater stabilization reagent (QIAGEN, Valencia, CA, USA) for 24$48 \mathrm{~h}$. The contralateral primary visual cortex $\left(1 \mathrm{~mm}^{3}\right.$ centered on Bregma: $-4 \mathrm{~mm}$, Interaural: $2.5 \mathrm{~mm}$ ) was dissected on ice within $60 \mathrm{~s}$ with RNAzap-treated instruments and stored at $-80^{\circ} \mathrm{C}$. Total RNA was extracted from the contralateral V1 using Qiazol reagent and the RNeasy ${ }^{\circledR}$ Lipid Tissue Mini Kit (QIAGEN, Valencia, CA, USA) according to the manufacturer's protocol. RNA concentration was determined using Nanodrop (ThermoFisher Scientific, Waltham, MA, USA), measuring 260/280 $\mathrm{nm}$ and 260/230 $\mathrm{nm}$ absorbance ratios. Real-time qPCR of 80 ng extracted RNA and specific primers (Table 1) was made using Quantifast ${ }^{\circledR}$ SYBR ${ }^{\circledR}$ Green RT-qPCR (QIAGEN, Valencia, CA, USA) using the manufacturer's protocol. Both targeted and referenced genes were amplified in duplicate on the same run. The relative quantification of each gene was determined using the MxProTM Q-PCR software version 3.00 (Stratagene, La Jolla, CA, USA), where the average of each duplicate mRNA levels was normalized by the $2^{-\Delta \Delta C t}$ methods (Livak and Schmittgen, 2001) using housekeeping genes $18 \mathrm{~S}$ and the non-conditioned group (naïve animal) as a control.

\section{Statistical Analysis}

The data were analyzed using GraphPad Prism software version 8 (GraphPad Software, San Diego, CA, USA). For the first experiment assessing sensitivity of the CaS to contrast and orientation $(n=18)$, outliers were detected and removed using the ROUT method $(\mathrm{Q}=1 \%)$ (Motulsky and Brown, 2006). To determine whether there was a significant modification in the area responses (Amplitude, Size, Latency, Persistence, and SNR) for the stimuli contrast (L, M, H), a Kruskal-Wallis test was performed individually for both orientations $\left(30^{\circ}\right.$ and $\left.90^{\circ}\right)$ in each area (cV1, iV1, PM, LM, RL, A, AM, AL, and RSC). To evaluate the difference between both orientation $(30$ and $90 \mathrm{H})$ responses, we used a one-tail Wilcoxon test as we expected a better response at $90^{\circ}$.

For the conditioning experiment, to investigate the treatments (i.e., Sham, CS and CS/DPZ, $n=5$ per group) and effects on the cortical response, we used the Wilcoxon matched pairs signed rank test on pre and post-conditioning responses for both orientations ( 30 vs. $90 \mathrm{H}$ ). Then, Kruskal-Wallis and uncorrected Dunn's tests were used to compare experimental groups in terms of post-pre responses for each stimulation pattern.

The activation- and resting state correlations were normalized using the Fisher Z-Transformation, then compared pre vs. post effects using $t$-tests $(n=5)$. A $t$-test was used to compare the post-conditioning of both conditioned groups. To enhance the clarity of the connectivity matrix, the heatmap was reorganized by putting high $r$ values closer to the diagonal line using the reorderMAT function (Brain Connectivity Toolbox, RRID:SCR_004841) on the pre-conditioning $(30 \mathrm{H})$ activation correlation $(n=18)$ and resting state $(n=18)$ matrices.

The normal distribution of RT-qPCR data was confirmed with the Kolmogorov-Smirnov test and compared using a two-way ANOVA and the Bonferroni's multiple comparisons test. Results were illustrated using bars graph representing mean \pm S.E.M., with a Pearson-coefficient correlation heatmap for clarity.

The statistical analysis was not corrected for multiple comparisons since this correction could lead to robust underevaluation of changes for a large number of comparisons (Rothman, 1990), as required for the statistical analysis of multiple cortical regions as seen here. All of the data and statistical results were presented instead. The data sets generated and/or analyzed during the current study are available from the corresponding author upon reasonable request.

\section{RESULTS}

\section{Selectivity of the Cortical Response Assessed by Mesoscale Calcium Imaging}

The sensitivity of the CaS to various contrasts or orientations was first evaluated in naïve animals $(n=18)$, in nine selected cortical areas involved at different levels of visual processing (cV1, iV1, PM, LM, RL, A, AM, AL, and RSC). These areas were selected because of their responsiveness to the stimulation ( $0.03 \mathrm{cpd}, 1 \mathrm{~Hz}$ sinusoidal grating). The responsiveness of other cortical areas was negligible and not reported. Note that the calcium signal in this Thy1-GCAMP6s line of mice mainly arises from the excitatory neurons and neurites of the superficial layers, although the GCaMP6s marker is expressed by $80 \%$ of pyramidal neurons in cortical layers $2 / 3$ and 5 (Dana et al., 2014). The CaS is negligible in GABAergic cells. Due to the density of the cortical tissue, the fluorescent signal from the superficial layers will have a stronger influence on the acquired signal compared to the signal from deeper layers, which will be more diffuse (Ma et al., 
2016). Different parameters were assessed to detect any change in neuronal encoding, i.e., the amplitude of the signal response (Amplitude) (Hendel et al., 2008), the proportion of the activated area (Size) (Kimura et al., 1999), the time before the maximal response (Latency) (Mentis et al., 2001), the persistence of the calcium response (Persistence) after the stimulus presentation, and the Signal-Noise ratio (SNR) (Rieke et al., 1999).

The pattern visual stimulation elicited a $\mathrm{CaS}$ increase in the majority of the observed areas, which was not significantly different between the stimulation conditions (orientation or contrast) in AL, AM, LM, RL, and RSC, but significantly affected by the stimulation conditions in PM and $\mathrm{V} 1$ according to the Kruskal-Wallis analysis. An increase in neuronal activity (amplitude) upon visual stimulation was detected in all examined regions (Table 2, Figures 2A, 3). Visually induced $\mathrm{CaS}$ was sensitive to contrast, particularly in cV1, iV1, PM, LM, and RSC (Figure 3). The amplitude of the CaS was identical for the two orientations of the grating $\left(30^{\circ}\right.$ or $\left.90^{\circ}\right)$. The other parameters studied were rarely affected by the contrast or orientation changes, though some isolated significant changes were detected: the size was significantly increased in $\mathrm{PM}$ for the $30^{\circ}$ orientation, and in $\mathrm{CV} 1$ for the $90^{\circ}$ orientation with higher contrast of the stimulation (Table 2, Figure 3), the latency of the peak response was dependent on the orientation in certain cortical areas (V1, $\mathrm{AL}$, and RSC), and the $90^{\circ}$ orientation induced a higher latency of the $\mathrm{CaS}_{\mathrm{Max}}$. Our results showed that the Persistence was also significantly higher for the $90^{\circ}$ orientation in V1 and AL (Table 2, Figure 3). SNR was affected by the contrast for both orientations only in $\mathrm{cV} 1$ (Table 2, Figure 3).

\section{Cortical Activation Mesoscale Maps After a Visual Conditioning Coupled With Saline or Cholinergic Potentiation}

The effect of the passive 1-week monocular visual conditioning associated or not with cholinergic potentiation on the cortical calcium response features (Amplitude, Size, Latency, and SNR) was then examined, as well as sham-conditioning (gray screen instead of gratings) (Figure 4, Tables 3-6). The normalized activation maps (via spatial Z-score transformation, see methods) showed a clear and localized activation of contralateral visual cortices in response to each visual stimulation for all of the mice. The ipsilateral cortex activity was not altered, except occasionally and faintly in the bilateral part of V1. The postconditioning CaS Amplitude values had a tendency to decrease compared to pre-values in all contralateral cortical areas for the $\mathrm{CS} / \mathrm{DPZ}$ group, with the exception of stimulation contrast in cV1 (Figure 4A) and PM (Figure 4C) and for the conditioned stimulus in AL (Figure 4B) and LM (Figure 4D). The Amplitude for the conditioned stimulus in the $\mathrm{CS}$ and sham groups decreased only for the lowest stimulation contrast (30 and $90 \mathrm{~L}$ ) after the conditioning, and there was no change in response to the non-conditioned stimulus (Table 3 ). The post-conditioning Size (Table 4) only decreased in $\mathrm{cV} 1$ (Figure 4A) and PM (Figure 4C). The other parameters were virtually unaffected by the conditioning, except for the SNR (Table 6) which was affected in the secondary visual area AL (Figure 4B) and PM
(Figure 4C) in the CS/DPZ group. The changes observed for the lower contrast of $50 \%$, even for Sham animals (Tables 36), were considered irrelevant as mice have poor visual acuity at this contrast, and that this low contrast pattern stimulus might be seen as a gray screen. Thus, the gray screen presented to the non-conditioned group might behave like a conditioned stimulus.

For the CS group, the changes elicited by the conditioning were highly variable between mice. The cortical response to the conditioned stimulus $(30 \mathrm{H})$ was in some cases reduced postconditioning compared to the pre-values for every contrast (30 L, $30 \mathrm{M}$, and $30 \mathrm{H}$ ), but this change was not significant (Figure 4B). In contradistinction, activation in the ipsilateral V1 (iV1) was measured when presenting the highest contrast stimuli (30 and $90 \mathrm{H})$. This activation was located in the upper-lateral region of $\mathrm{iV} 1$, corresponding to the binocular region of this cortex (Figure 2). There was no observable modification of the CaS after the 1-week conditioning for the non-conditioned stimulus $(90 \mathrm{H}$, Figures 4A-D). The monocular visual conditioning caused a significant decrease in the Amplitude on D8 for the lowest contrast of the conditioned orientation (30 L), only in the cV1, $\mathrm{PM}$, and RL cortices (Table 3). The modification in the Size (Table 4) of the responses was highly variable between mice in $\mathrm{AL}$ (Figure 4B) and LM (Figure 4D), but none were significantly diminished. The Latency (Table 5) was not significantly modified in any areas for any stimulation. The SNR (Table 6) was significantly reduced in response to the lowest stimulation contrast (30 L) in A and RL.

For the CS/DPZ group, the variability of the results was much lower. The Amplitude in response to the conditioned stimuli was significantly decreased on D8 in $\mathrm{CV} 1$ (Figure 4A) and PM (Figure 4C) (30 L, $30 \mathrm{M}$, and $30 \mathrm{H}), \mathrm{AM}$ and RL (30 M and $30 \mathrm{H}$ ), and AL (Figure 4B) and LM (Figure 4D) $(30 \mathrm{H})$ (Table 3). The non-conditioned stimulus $(90 \mathrm{H})$ was not affected in any visual areas (Figure 4). The comparison of the response amplitude of both orientations $(30$ vs. $90 \mathrm{H})$ at $\mathrm{D} 8$ showed a significant difference in iV1, AM, PM, RL, and RSC following the DPZ treatment, whereas this difference was not observable on D0. Additionally, the Friedman analysis showed that the Amplitude response to the different contrasts $(30 \mathrm{~L}, 30 \mathrm{M}$, and $30 \mathrm{H}$ ) was not significant after the treatment in $\mathrm{CV} 1, \mathrm{AL}, \mathrm{PM}$, and $\mathrm{LM}$ (Figure 4), even though it was before the conditioning. The Size was significantly reduced in response to the CS/DPZ group in cV1 (Figure 4A) $(30 \mathrm{H}), \mathrm{AM}$ and RL $(30 \mathrm{M})$, and in the PM cortex $(30 \mathrm{~L}, 30 \mathrm{M}$, and $30 \mathrm{H}$, Figure $4 \mathrm{C}$ ). A significant difference in the size between both orientations $(30$ vs. $90 \mathrm{H})$ was observable on D8, only in PM. Finally, the cholinergic potentiation of the conditioning had a significant influence on the SNR (Table 6) in multiple visual cortices and the PM cortex $(30 \mathrm{~L}, 30 \mathrm{M}$, and $30 \mathrm{H}$, Figure 4C), as well as in $\mathrm{cV} 1$ (30 L and $30 \mathrm{M})$, AL (Figure 4B), $\mathrm{AM}$ and $\mathrm{RL}(30 \mathrm{M}$ and $30 \mathrm{H})$, and $\mathrm{A}(30 \mathrm{H})$. The Latency and the Persistence were not affected following the cholinergic potentiation. Finally, no significant modification of any $\mathrm{CaS}$ parameters was observed in response to the $90 \mathrm{H}$ stimulation (Figure 4, Tables 3-6).

When comparing of the post-pre variation, the Amplitude was significantly modified by treatments in PM for all contrasts 
TABLE 2 | Response parameters in function of the stimulation contrast and orientation.

\begin{tabular}{|c|c|c|c|c|c|c|}
\hline Area & Stim. & Amplitude ( $\Delta F / F, \%)$ & Size (Prop.) & Latency (ms) & Persistence (ms) & SNR \\
\hline \multirow[t]{4}{*}{$\mathrm{cV} 1$} & $30 \mathrm{~L}$ & $0.39 \pm 0.04$ & $0.85 \pm 0.03$ & $11.22 \pm 0.44$ & $20.59 \pm 0.45$ & $13.26 \pm 1.08$ \\
\hline & $30 \mathrm{M}$ & $0.47 \pm 0.05$ & $0.86 \pm 0.03$ & $11.06 \pm 0.44$ & $20.69 \pm 0.44$ & $15.26 \pm 1.18$ \\
\hline & $90 \mathrm{~L}$ & $0.38 \pm 0.04$ & $0.75 \pm 0.06$ & $12.83 \pm 0.50$ & $22.25 \pm 1.20$ & $14.32 \pm 1.50$ \\
\hline & $90 \mathrm{M}$ & $0.46 \pm 0.06$ & $0.86 \pm 0.03$ & $11.50 \pm 0.51$ & $22.13 \pm 0.90$ & $10.17 \pm 1.25$ \\
\hline & $30 \mathrm{M}$ & $0.46 \pm 0.04$ & $0.96 \pm 0.01$ & $10.33 \pm 0.40$ & $19.94 \pm 0.51$ & $8.51 \pm 1.49$ \\
\hline & $30 \mathrm{H}$ & $0.56 \pm 0.05$ & $0.97 \pm 0.01$ & $10.33 \pm 0.32$ & $20.63 \pm 0.54$ & $9.22 \pm 1.62$ \\
\hline & $90 \mathrm{~L}$ & $0.38 \pm 0.04$ & $0.89 \pm 0.03$ & $12.33 \pm 0.50$ & $21.07 \pm 1.10$ & $7.08 \pm 1.25$ \\
\hline & $90 \mathrm{M}$ & $0.45 \pm 0.04$ & $0.96 \pm 0.01$ & $11.50 \pm 0.47$ & $19.63 \pm 1.03$ & $6.48 \pm 1.28$ \\
\hline & $90 \mathrm{H}$ & $0.54 \pm 0.05$ & $0.92 \pm 0.02$ & $11.56 \pm 0.57$ & $21.18 \pm 0.89$ & $8.76 \pm 1.67$ \\
\hline & $90 \mathrm{~L}$ & $0.17 \pm 0.02$ & $0.65 \pm 0.08$ & $12.50 \pm 0.65$ & $19.35 \pm 1.68$ & $4.77 \pm 0.92$ \\
\hline & $90 \mathrm{M}$ & $0.23 \pm 0.03$ & $0.69 \pm 0.07$ & $11.06 \pm 0.70$ & $17.19 \pm 0.98$ & $4.87 \pm 1.01$ \\
\hline & $90 \mathrm{H}$ & $0.27 \pm 0.03$ & $0.72 \pm 0.06$ & $12.71 \pm 0.49$ & $19.41 \pm 1.30$ & $6.16 \pm 1.23$ \\
\hline \multirow[t]{6}{*}{ A } & $30 \mathrm{~L}$ & $0.18 \pm 0.02$ & $0.34 \pm 0.08$ & $10.06 \pm 1.00$ & $15.59 \pm 0.91$ & $3.60 \pm 0.70$ \\
\hline & $30 \mathrm{M}$ & $0.20 \pm 0.04$ & $0.40 \pm 0.08$ & $8.50 \pm 0.44$ & $14.18 \pm 1.49$ & $3.90 \pm 0.94$ \\
\hline & $30 \mathrm{H}$ & $0.20 \pm 0.04$ & $0.33 \pm 0.07$ & $9.83 \pm 0.82$ & $14.00 \pm 1.21$ & $3.10 \pm 0.61$ \\
\hline & $90 \mathrm{~L}$ & $0.17 \pm 0.03$ & $0.21 \pm 0.03$ & $11.39 \pm 0.70$ & $14.53 \pm 1.76$ & $2.57 \pm 0.52$ \\
\hline & $90 \mathrm{M}$ & $0.18 \pm 0.03$ & $0.33 \pm 0.07$ & $11.72 \pm 0.80$ & $15.00 \pm 1.61$ & $2.54 \pm 0.48$ \\
\hline & $90 \mathrm{H}$ & $0.22 \pm 0.03$ & $0.30 \pm 0.07$ & $11.17 \pm 0.97$ & $16.71 \pm 1.23$ & $3.36 \pm 0.69$ \\
\hline \multirow[t]{2}{*}{ AL } & $30 \mathrm{~L}$ & $0.27 \pm 0.03$ & $0.71 \pm 0.07$ & $10.56 \pm 0.62$ & $19.07 \pm 0.38$ & $5.52 \pm 0.96$ \\
\hline & $30 \mathrm{M}$ & $0.31 \pm 0.05$ & $0.72 \pm 0.07$ & $10.94 \pm 0.45$ & $18.36 \pm 0.52$ & $5.45 \pm 1.01$ \\
\hline & $30 \mathrm{H}$ & $0.25 \pm 0.04$ & $0.41 \pm 0.06$ & $10.61 \pm 0.70$ & $16.47 \pm 1.33$ & $4.18 \pm 0.79$ \\
\hline & $90 \mathrm{~L}$ & $0.21 \pm 0.03$ & $0.40 \pm 0.07$ & $12.00 \pm 0.67$ & $17.69 \pm 1.78$ & $3.94 \pm 0.84$ \\
\hline & $90 \mathrm{M}$ & $0.22 \pm 0.04$ & $0.39 \pm 0.07$ & $12.28 \pm 0.66$ & $19.00 \pm 1.54$ & $2.93 \pm 0.52$ \\
\hline & $90 \mathrm{H}$ & $0.26 \pm 0.04$ & $0.34 \pm 0.06$ & $12.00 \pm 0.94$ & $18.29 \pm 1.42$ & $4.45 \pm 0.979$ \\
\hline \multirow[t]{6}{*}{$\mathrm{RL}$} & $30 \mathrm{~L}$ & $0.21 \pm 0.02$ & $0.59 \pm 0.07$ & $9.72 \pm 0.80$ & $17.41 \pm 0.62$ & $4.38 \pm 0.76$ \\
\hline & $30 \mathrm{M}$ & $0.20 \pm 0.02$ & $0.64 \pm 0.08$ & $11.67 \pm 0.56$ & $18.18 \pm 0.69$ & $4.86 \pm 1.00$ \\
\hline & $30 \mathrm{H}$ & $0.25 \pm 0.04$ & $0.63 \pm 0.05$ & $11.67 \pm 0.56$ & $16.88 \pm 0.69$ & $4.53 \pm 0.86$ \\
\hline & $90 \mathrm{~L}$ & $0.17 \pm 0.02$ & $0.56 \pm 0.06$ & $11.61 \pm 0.81$ & $17.53 \pm 1.54$ & $3.52 \pm 0.63$ \\
\hline & $90 \mathrm{M}$ & $0.23 \pm 0.03$ & $0.59 \pm 0.07$ & $10.28 \pm 0.74$ & $16.69 \pm 1.12$ & $3.08 \pm 0.56$ \\
\hline & $90 \mathrm{H}$ & $0.27 \pm 0.03$ & $0.58 \pm 0.07$ & $11.61 \pm 0.82$ & $18.47 \pm 1.01$ & $4.74 \pm 0.93$ \\
\hline \multirow[t]{6}{*}{ RSC } & $30 \mathrm{~L}$ & $0.10 \pm 0.01$ & $0.39 \pm 0.03$ & $10.89 \pm 0.52$ & $13.53 \pm 0.72$ & $3.16 \pm 0.52$ \\
\hline & $30 \mathrm{M}$ & $0.14 \pm 0.02$ & $0.44 \pm 0.04$ & $10.59 \pm 0.46$ & $16.41 \pm 1.21$ & $3.52 \pm 0.62$ \\
\hline & $30 \mathrm{H}$ & $0.16 \pm 0.02$ & $0.48 \pm 0.04$ & $9.39 \pm 0.43$ & $15.06 \pm 0.59$ & $3.28 \pm 0.52$ \\
\hline & $90 \mathrm{~L}$ & $0.10 \pm 0.01$ & $0.39 \pm 0.05$ & $11.06 \pm 0.93$ & $12.94 \pm 1.67$ & $2.74 \pm 0.40$ \\
\hline & $90 \mathrm{M}$ & $0.13 \pm 0.02$ & $0.43 \pm 0.05$ & $10.28 \pm 0.74$ & $14.07 \pm 0.85$ & $2.36 \pm 0.40$ \\
\hline & $90 \mathrm{H}$ & $0.15 \pm 0.02$ & $0.46 \pm 0.04$ & $11.06 \pm 0.59$ & $15.94 \pm 1.02$ & $3.62 \pm 0.67$ \\
\hline
\end{tabular}

Values represent parameters (Amplitude, Size, Latency, Persistence and SNR) of response to the visual stimulation (30 L: $30^{\circ}, 50 \% ; 30 \mathrm{M:} 30^{\circ}, 75 \% ; 30 \mathrm{H:} 30^{\circ}, 100 \% ; 90 \mathrm{L:}: 90^{\circ}, 50 \%$; 90 M: $90^{\circ}, 75 \% ; 90 \mathrm{H}: 90^{\circ}, 100 \%$ ) (means \pm S.E.M.), $30 \mathrm{~L}$ or $90 \mathrm{~L}$. Bold characters represent significant value. $p \leq 0.05$ compared to low contrast counterparts; Underline characters represent significant values comparing $30 \mathrm{H}$ response to $90 \mathrm{H} . \mathrm{p} \leq 0.05$ compared to $90 \mathrm{H}$. 


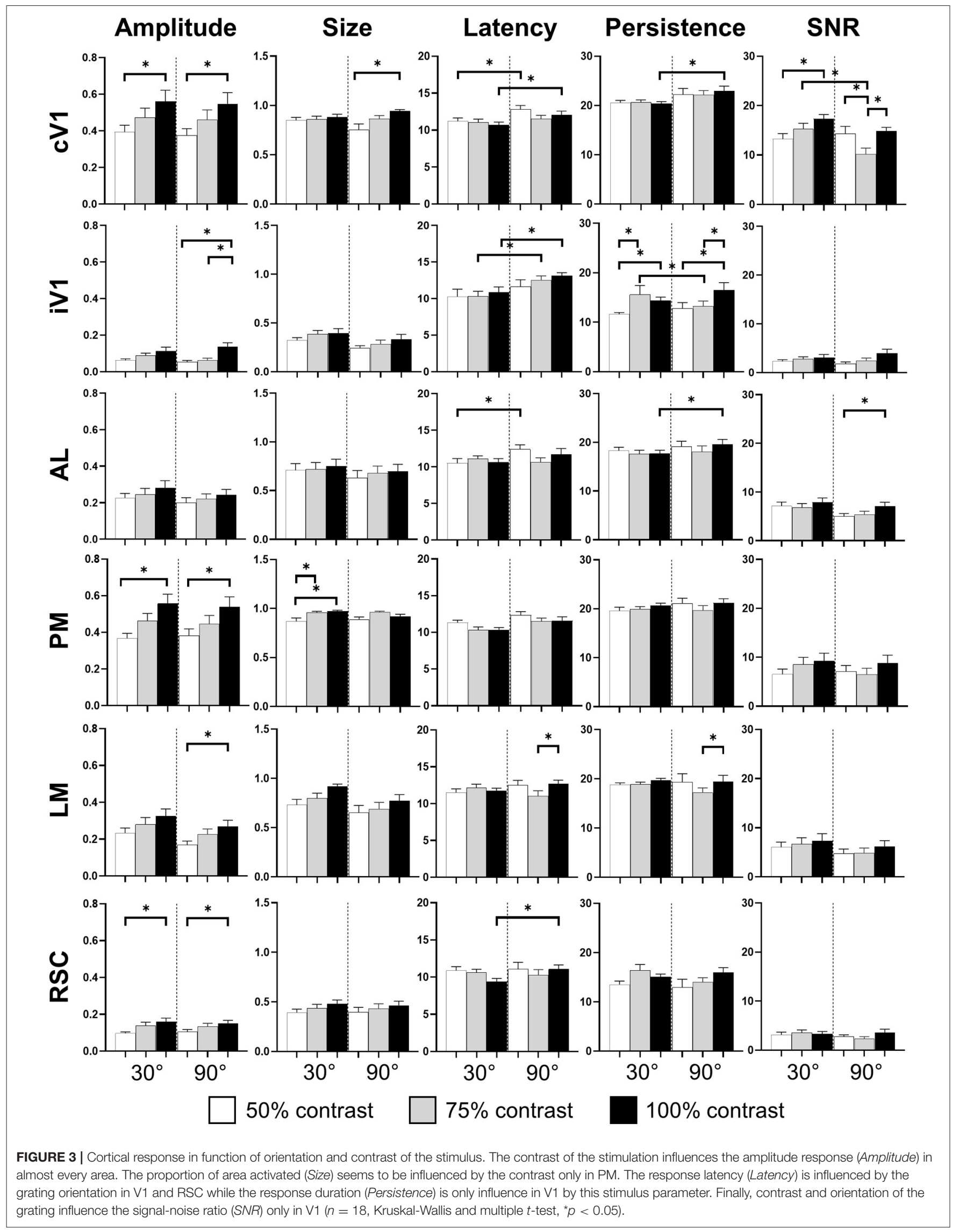




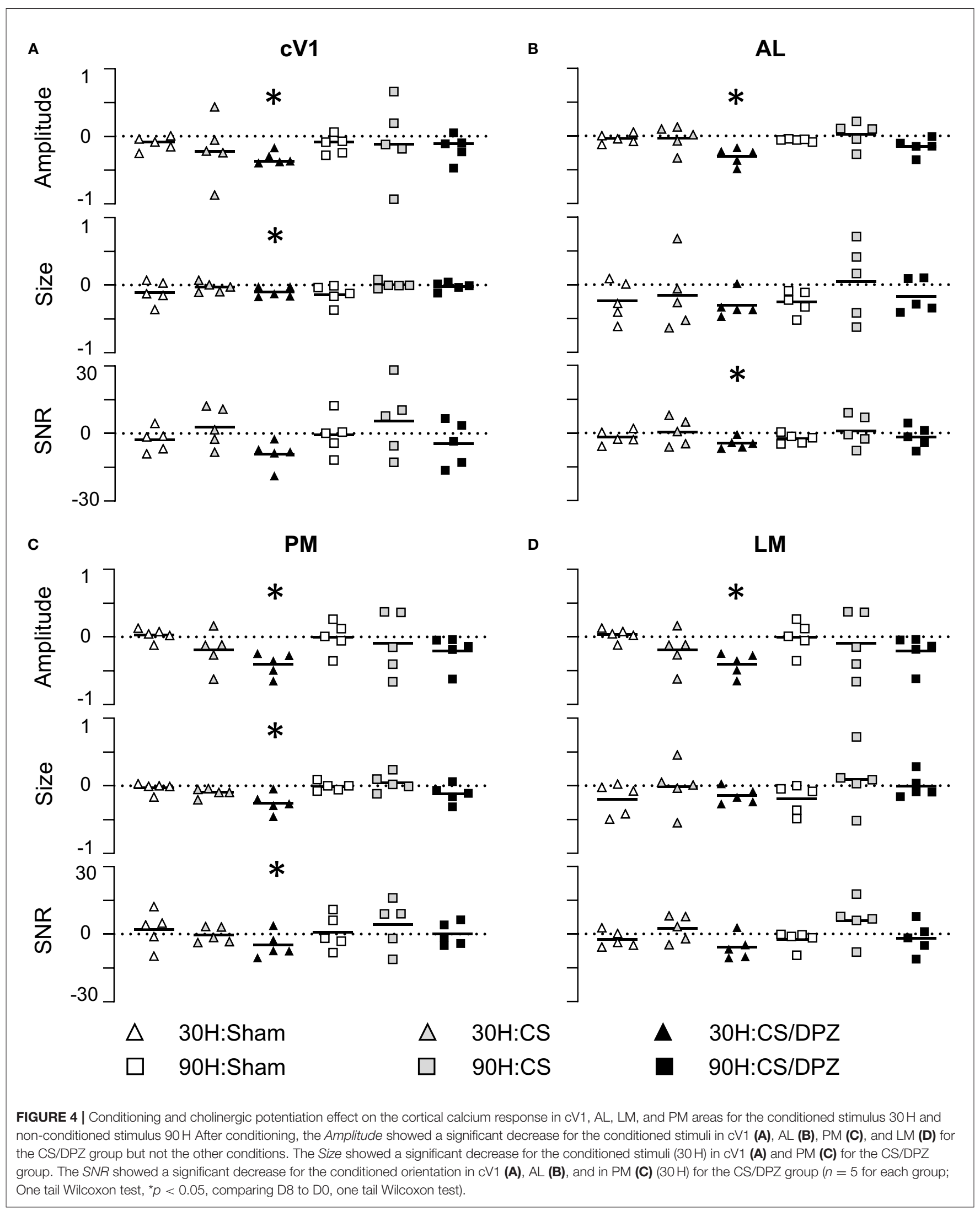


TABLE 3 | Modification in the Amplitude ( $\triangle$ Post-Pre cortical response) of the visual stimulation.

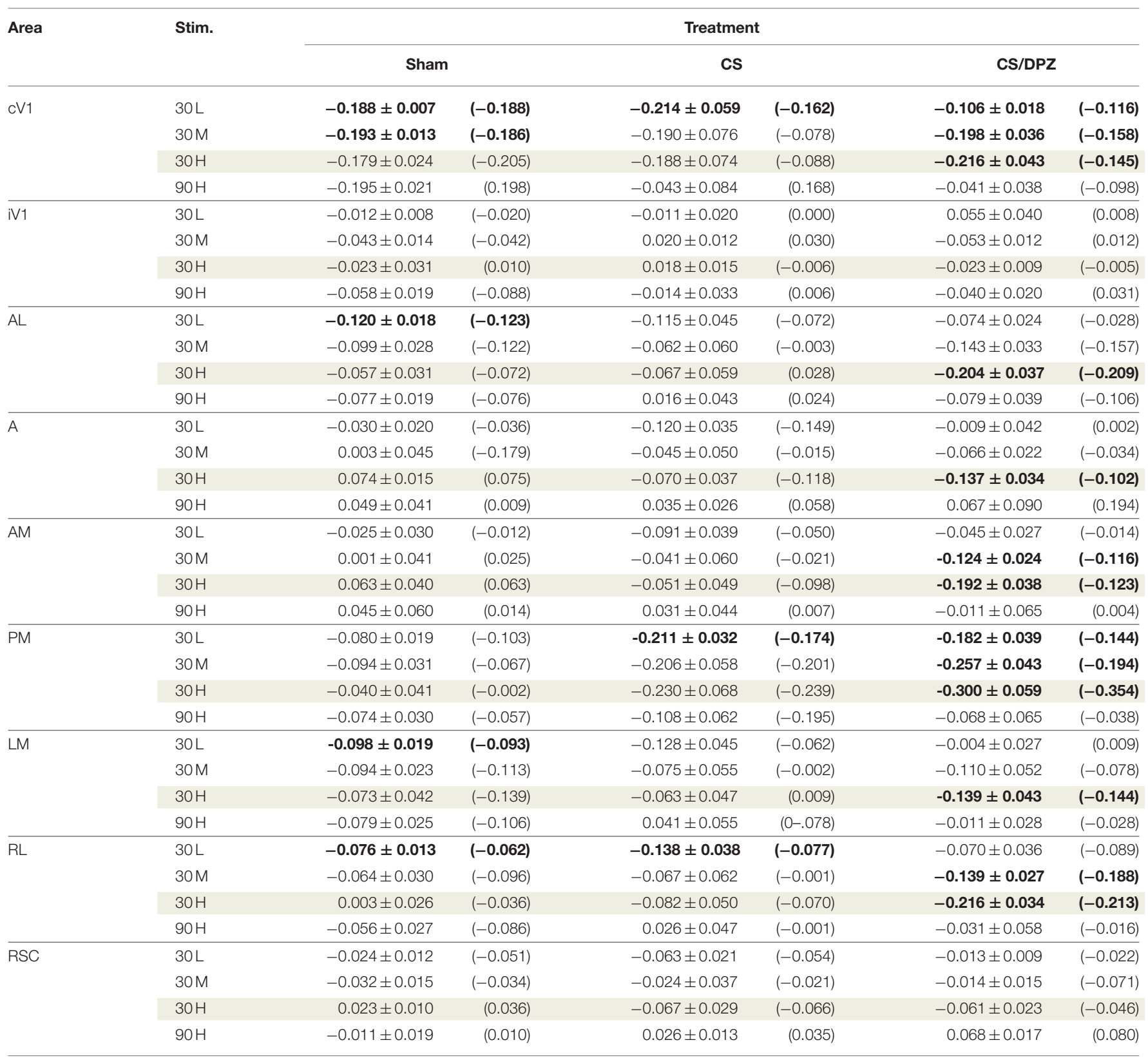

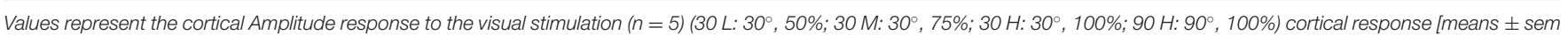

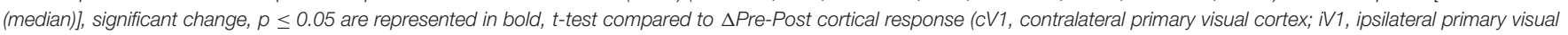

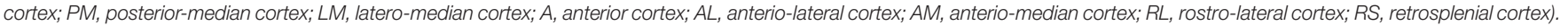
The values corresponding to the conditioned stimulus $(30 \mathrm{H})$ are underlined in gray.

of the conditioned orientation $(30 \mathrm{~L}, 30 \mathrm{M}$, and $30 \mathrm{H})$, but not for the non-conditioned stimulus $(90 \mathrm{H})$. The multiple comparisons showed that this modification occurred between the non-conditioned group and the DPZ conditioning group, while no significant difference was observable between both conditioned groups. This modification was also observable in $\mathrm{AL}(30 \mathrm{M}$ and $30 \mathrm{H})$ and $\mathrm{RL}(30 \mathrm{H})$. Despite the Kruskal-Wallis test not showing any significant effect of the treatments in $\mathrm{cV} 1$ and AM, multiple comparisons showed a clear significant effect between non-conditioned and DPZ groups $(30 \mathrm{H})$. The only significant differences between $\mathrm{CS}$ and $\mathrm{CS} / \mathrm{DPZ}$ groups were observed in RL and AL for the conditioned stimulus $(30 \mathrm{H})$. For the Size, our results showed that there was a significant modification in PM for two contrasts of the conditioned stimulus ( $30 \mathrm{M}$ and $30 \mathrm{H}$ ), both significant diminutions occurring between the non-conditioned and the CS/DPZ group. For the 
TABLE 4 | Modification in the Size ( $\triangle$ Post-Pre cortical response) in response of the visual stimulation.

\begin{tabular}{|c|c|c|c|c|c|c|c|}
\hline \multirow{3}{*}{$\begin{array}{l}\text { Area } \\
\mathrm{cV} 1\end{array}$} & \multirow{3}{*}{$\begin{array}{l}\text { Stim. } \\
30 \mathrm{~L}\end{array}$} & \multicolumn{6}{|c|}{ Treatment } \\
\hline & & \multicolumn{2}{|c|}{ Sham } & \multicolumn{2}{|c|}{ CS } & \multicolumn{2}{|c|}{ CS/DPZ } \\
\hline & & $-0.004 \pm 0.145$ & $(-0.124)$ & $-0.169 \pm 0.190$ & $(-0.301)$ & $-0.048 \pm 0.014$ & $(-0.054)$ \\
\hline & $30 \mathrm{M}$ & $0.024 \pm 0.166$ & $(-0.128)$ & $-0.009 \pm 0.192$ & $(-0.018)$ & $-0.083 \pm 0.030$ & $(-0.046)$ \\
\hline & $30 \mathrm{H}$ & $0.022 \pm 0.173$ & $(-0.146)$ & $-0.008 \pm 0.198$ & $(0.073)$ & $-0.088 \pm 0.017$ & $(-0.101)$ \\
\hline & $90 \mathrm{H}$ & $-0.005 \pm 0.162$ & $(-0.157)$ & $0.019 \pm 0.183$ & $(0.082)$ & $0.006 \pm 0.019$ & $(-0.007)$ \\
\hline \multirow[t]{4}{*}{ iV1 } & $30 \mathrm{~L}$ & $-0.041 \pm 0.054$ & $(0.026)$ & $-0.051 \pm 0.069$ & $(-0.155)$ & $-0.009 \pm 0.037$ & $(-0.008)$ \\
\hline & $30 \mathrm{M}$ & $-0.100 \pm 0.032$ & $(-0.060)$ & $0.077 \pm 0.030$ & $(0.091)$ & $-0.013 \pm 0.038$ & $(-0.014)$ \\
\hline & $30 \mathrm{H}$ & $-0.090 \pm 0.090$ & $(-0.072)$ & $0.062 \pm 0.051$ & $(0.067)$ & $0.063 \pm 0.024$ & $(0.070)$ \\
\hline & $90 \mathrm{H}$ & $-0.086 \pm 0.050$ & $(-0.095)$ & $0.076 \pm 0.064$ & $(0.035)$ & $0.127 \pm 0.041$ & $(0.154)$ \\
\hline \multirow[t]{4}{*}{$A L$} & $30 \mathrm{~L}$ & $-0.217 \pm 0.134$ & $(-0.336)$ & $-0.074 \pm 0.171$ & $(0.041)$ & $-0.164 \pm 0.071$ & $(-0.068)$ \\
\hline & $30 \mathrm{M}$ & $-0.093 \pm 0.129$ & $(-0.143)$ & $0.027 \pm 0.165$ & $(0.300)$ & $-0.228 \pm 0.042$ & $(-0.212)$ \\
\hline & $30 \mathrm{H}$ & $-0.164 \pm 0.156$ & $(-0.344)$ & $-0.029 \pm 0.224$ & $(-0.059)$ & $-0.276 \pm 0.065$ & $(-0.328)$ \\
\hline & $90 \mathrm{H}$ & $-0.178 \pm 0.147$ & $(-0.414)$ & $0.164 \pm 0.200$ & $(0.412)$ & $-0.065 \pm 0.139$ & $(-0.213)$ \\
\hline \multirow[t]{4}{*}{ A } & $30 \mathrm{~L}$ & $0.245 \pm 0.095$ & $(0.124)$ & $0.131 \pm 0.080$ & $(0.108)$ & $0.073 \pm 0.152$ & $(-0.008)$ \\
\hline & $30 \mathrm{M}$ & $0.195 \pm 0.089$ & $(0.058)$ & $0.255 \pm 0.081$ & $(0.172)$ & $-0.182 \pm 0.073$ & $(-0.164)$ \\
\hline & $30 \mathrm{H}$ & $0.214 \pm 0.076$ & $(0.171)$ & $0.100 \pm 0.138$ & $(-0.021)$ & $-0.045 \pm 0.131$ & $(-0.138)$ \\
\hline & $90 \mathrm{H}$ & $0.262 \pm 0.113$ & $(0.125)$ & $0.263 \pm 0.129$ & $(0.101)$ & $0.018 \pm 0.154$ & (0.010) \\
\hline \multirow[t]{4}{*}{ AM } & $30 \mathrm{~L}$ & $0.197 \pm 0.114$ & $(0.123)$ & $0.178 \pm 0.096$ & $(0.223)$ & $0.045 \pm 0.130$ & (0.129) \\
\hline & $30 \mathrm{M}$ & $0.170 \pm 0.134$ & $(0.160)$ & $0.217 \pm 0.104$ & (0.235) & $-0.208 \pm 0.031$ & $(-0.191)$ \\
\hline & $30 \mathrm{H}$ & $0.199 \pm 0.116$ & $(0.129)$ & $0.127 \pm 0.151$ & $(-0.184)$ & $-0.210 \pm 0.101$ & $(-0.246)$ \\
\hline & $90 \mathrm{H}$ & $0.231 \pm 0.140$ & $(0.080)$ & $0.295 \pm 0.131$ & $(0.256)$ & $-0.051 \pm 0.125$ & $(0.024)$ \\
\hline \multirow[t]{4}{*}{ PM } & $30 \mathrm{~L}$ & $0.139 \pm 0.133$ & $(0.000)$ & $-0.170 \pm 0.180$ & $(-0.316)$ & $-0.273 \pm 0.033$ & $(-0.239)$ \\
\hline & $30 \mathrm{M}$ & $0.118 \pm 0.149$ & $(-0.014)$ & $-0.034 \pm 0.175$ & $(-0.047)$ & $-0.268 \pm 0.045$ & $(-0.240)$ \\
\hline & $30 \mathrm{H}$ & $0.143 \pm 0.147$ & $(0.000)$ & $-0.088 \pm 0.191$ & $(-0.041)$ & $-0.260 \pm 0.050$ & $(-0.265)$ \\
\hline & $90 \mathrm{H}$ & $0.150 \pm 0.142$ & $(-0.054)$ & $0.048 \pm 0.211$ & (0.099) & $-0.076 \pm 0.047$ & $(-0.067)$ \\
\hline \multirow[t]{4}{*}{ LM } & $30 \mathrm{~L}$ & $-0.059 \pm 0.125$ & $(-0.230)$ & $-0.118 \pm 0.181$ & $(-0.230)$ & $-0.044 \pm 0.055$ & $(-0.119)$ \\
\hline & $30 \mathrm{M}$ & $-0.058 \pm 0.159$ & $(-0.351)$ & $0.075 \pm 0.195$ & $(0.049)$ & $-0.124 \pm 0.068$ & $(-0.068)$ \\
\hline & $30 \mathrm{H}$ & $-0.141 \pm 0.183$ & $(-0.495)$ & $0.087 \pm 0.207$ & $(0.053)$ & $-0.099 \pm 0.044$ & $(-0.048)$ \\
\hline & $90 \mathrm{H}$ & $-0.142 \pm 0.161$ & $(-0.479)$ & $0.175 \pm 0.225$ & $(0.117)$ & $0.099 \pm 0.066$ & (0.039) \\
\hline \multirow[t]{4}{*}{$\mathrm{RL}$} & $30 \mathrm{~L}$ & $0.022 \pm 0.132$ & $(-0.127)$ & $0.027 \pm 0.161$ & $(0.120)$ & $-0.178 \pm 0.095$ & $(-0.257)$ \\
\hline & $30 \mathrm{M}$ & $0.095 \pm 0.125$ & $(-0.069)$ & $0.090 \pm 0.152$ & $(0.234)$ & $-0.242 \pm 0.057$ & $(-0.304)$ \\
\hline & $30 \mathrm{H}$ & $0.069 \pm 0.140$ & $(-0.044)$ & $-0.077 \pm 0.176$ & $(-0.258)$ & $-0.381 \pm 0.104$ & $(-0.598)$ \\
\hline & $90 \mathrm{H}$ & $0.054 \pm 0.145$ & $(-0.127)$ & $0.177 \pm 0.182$ & $(0.143)$ & $-0.070 \pm 0.149$ & $(0.017)$ \\
\hline \multirow[t]{4}{*}{ RSC } & $30 \mathrm{~L}$ & $-0.038 \pm 0.052$ & $(-0.074)$ & $-0.012 \pm 0.082$ & $(0.057)$ & $-0.022 \pm 0.054$ & $(-0.065)$ \\
\hline & $30 \mathrm{M}$ & $-0.029 \pm 0.055$ & $(-0.119)$ & $0.098 \pm 0.052$ & (0.159) & $-0.031 \pm 0.043$ & $(-0.009)$ \\
\hline & $30 \mathrm{H}$ & $0.068 \pm 0.051$ & $(0.051)$ & $-0.030 \pm 0.085$ & $(-0.168)$ & $-0.073 \pm 0.039$ & $(-0.062)$ \\
\hline & $90 \mathrm{H}$ & $-0.059 \pm 0.090$ & $(-0.227)$ & $0.101 \pm 0.094$ & $(0.149)$ & $0.134 \pm 0.014$ & (0.132) \\
\hline
\end{tabular}

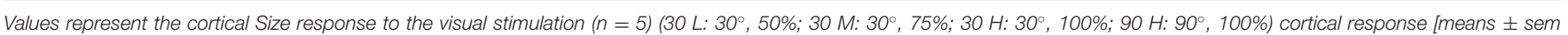

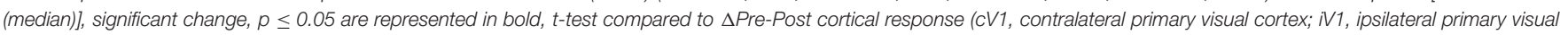

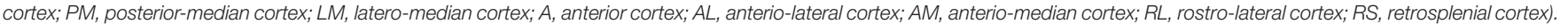
The values corresponding to the conditioned stimulus $(30 \mathrm{H})$ are underlined in gray.

Latency, only the response in AM was significantly changed for the conditioned stimulus $(30 \mathrm{H})$, expressed by a significant diminution of Latency between the non-conditioned and the CS/DPZ group. Lastly, for the SNR, we observed a significant change for the conditioned stimulus $(30 \mathrm{H})$ in $c V 1$ and LM; this significant diminution of the SNR was shown between both conditioned groups (CS vs. DPZ). Interestingly, while the variation was low for the sham and CS/DPZ groups, the conditioning alone caused high interindividual variability in the treatment effect.

\section{Activation Correlations}

The co-activation of the cortical areas elicited by the conditioned $\left(30^{\circ}\right)$ or non-conditioned $\left(90^{\circ}\right)$ orientation presentation was evaluated using the Pearson's Correlation analysis (Figure 5) at D0 and D8. To highlight significant modifications in the activation correlation, results from both days were transformed using the Fisher Z-Transformation, allowing for $t$-test comparisons.

Before the conditioning, the activation correlation was similar for $30 \mathrm{H}$ or $90 \mathrm{H}$. All selected areas of the visual system were 
TABLE 5 | Modification in the Latency ( $\triangle$ Post-Pre cortical response) in response of the visual stimulation.

\begin{tabular}{|c|c|c|c|c|c|c|c|}
\hline \multirow{3}{*}{$\begin{array}{l}\text { Area } \\
\mathrm{cV} 1\end{array}$} & \multirow{3}{*}{$\begin{array}{l}\text { Stim. } \\
30 \mathrm{~L}\end{array}$} & \multicolumn{6}{|c|}{ Treatment } \\
\hline & & \multicolumn{2}{|c|}{ Sham } & \multicolumn{2}{|l|}{ CS } & \multicolumn{2}{|c|}{ CS/DPZ } \\
\hline & & $1.800 \pm 0.611$ & $(2.000)$ & $0.000 \pm 0.699$ & $(1.000)$ & $0.400 \pm 0.806$ & $(0.000)$ \\
\hline & $30 \mathrm{M}$ & $1.400 \pm 0.686$ & $(1.000)$ & $0.000 \pm 0.558$ & $(0.000)$ & $-0.200 \pm 1.020$ & $(-2.000)$ \\
\hline & $30 \mathrm{H}$ & $1.000 \pm 0.632$ & $(1.000)$ & $-0.600 \pm 0.581$ & $(-2.000)$ & $0.600 \pm 0.452$ & $(0.000)$ \\
\hline & $90 \mathrm{H}$ & $2.000 \pm 0.558$ & $(2.000)$ & $1.000 \pm 1.054$ & $(1.000)$ & $-1.200 \pm 0.998$ & $(-1.000)$ \\
\hline \multirow[t]{4}{*}{ iV1 } & $30 \mathrm{~L}$ & $-1.600 \pm 1.024$ & $(-3.000)$ & $1.800 \pm 1.638$ & $(5.000)$ & $-2.800 \pm 2.736$ & $(-3.000)$ \\
\hline & $30 \mathrm{M}$ & $0.200 \pm 0.998$ & $(-1.000)$ & $0.000 \pm 0.760$ & $(1.000)$ & $-2.400 \pm 0.618$ & $(-2.000)$ \\
\hline & $30 \mathrm{H}$ & $0.200 \pm 0.879$ & $(0.000)$ & $0.600 \pm 0.777$ & $(2.000)$ & $0.800 \pm 1.143$ & $(0.000)$ \\
\hline & $90 \mathrm{H}$ & $-1.000 \pm 0.869$ & $(0.000)$ & $0.200 \pm 1.806$ & $(-1.000)$ & $-1.000 \pm 0.789$ & $(0.000)$ \\
\hline \multirow[t]{4}{*}{$A L$} & $30 \mathrm{~L}$ & $0.800 \pm 1.718$ & $(2.000)$ & $2.000 \pm 0.760$ & $(2.000)$ & $-0.600 \pm 0.884$ & $(-1.000)$ \\
\hline & $30 \mathrm{M}$ & $-0.200 \pm 0.573$ & $(0.000)$ & $-0.600 \pm 0.581$ & $(0.000)$ & $-0.600 \pm 0.618$ & $(-1.000)$ \\
\hline & $30 \mathrm{H}$ & $1.000 \pm 0.422$ & $(2.000)$ & $-1.400 \pm 1.258$ & $(-2.000)$ & $-1.400 \pm 1.514$ & $(-2.000)$ \\
\hline & $90 \mathrm{H}$ & $2.400 \pm 0.542$ & $(2.000)$ & $0.800 \pm 1.356$ & $(2.000)$ & $-2.600 \pm 2.237$ & $(-1.000)$ \\
\hline \multirow[t]{4}{*}{$A$} & $30 \mathrm{~L}$ & $0.800 \pm 1.611$ & $(-1.000)$ & $1.400 \pm 1.166$ & $(2.000)$ & $-1.800 \pm 1.971$ & $(-2.000)$ \\
\hline & $30 \mathrm{M}$ & $5.600 \pm 1.694$ & $(4.000)$ & $1.000 \pm 2.055$ & $(-1.000)$ & $0.200 \pm 1.254$ & $(-1.000)$ \\
\hline & $30 \mathrm{H}$ & $1.800 \pm 0.827$ & $(1.000)$ & $3.200 \pm 1.855$ & $(2.000)$ & $-4.000 \pm 1.660$ & $(-5.000)$ \\
\hline & $90 \mathrm{H}$ & $-2.000 \pm 1.174$ & $(-2.000)$ & $1.800 \pm 1.451$ & $(2.000)$ & $-4.200 \pm 1.718$ & $(-5.000)$ \\
\hline \multirow[t]{4}{*}{ AM } & $30 \mathrm{~L}$ & $2.200 \pm 0.533$ & $(2.000)$ & $-1.400 \pm 1.046$ & $(-1.000)$ & $-0.400 \pm 1.939$ & $(-1.000)$ \\
\hline & $30 \mathrm{M}$ & $1.600 \pm 0.581$ & $(3.000)$ & $4.000 \pm 1.592$ & $(3.000)$ & $0.800 \pm 1.236$ & $(3.000)$ \\
\hline & $30 \mathrm{H}$ & $3.000 \pm 1.414$ & $(3.000)$ & $1.600 \pm 0.653$ & $(0.000)$ & $-4.600 \pm 1.833$ & $(-3.000)$ \\
\hline & $90 \mathrm{H}$ & $0.000 \pm 1.193$ & $(-2.000)$ & $0.400 \pm 1.833$ & $(-1.000)$ & $-2.000 \pm 2.211$ & $(1.000)$ \\
\hline \multirow[t]{4}{*}{ PM } & $30 \mathrm{~L}$ & $2.200 \pm 0.490$ & $(3.000)$ & $0.000 \pm 0.596$ & $(0.000)$ & $-0.200 \pm 0.442$ & $(0.000)$ \\
\hline & $30 \mathrm{M}$ & $2.000 \pm 0.843$ & $(3.000)$ & $-0.400 \pm 0.400$ & $(-1.000)$ & $0.200 \pm 0.929$ & $(-1.000)$ \\
\hline & $30 \mathrm{H}$ & $0.200 \pm 0.533$ & $(-1.000)$ & $0.000 \pm 0.558$ & $(1.000)$ & $0.400 \pm 0.653$ & $(-1.000)$ \\
\hline & $90 \mathrm{H}$ & $1.000 \pm 0.966$ & $(1.000)$ & $0.200 \pm 1.482$ & $(-2.000)$ & $0.600 \pm 1.002$ & $(1.000)$ \\
\hline \multirow[t]{4}{*}{ LM } & $30 \mathrm{~L}$ & $1.400 \pm 1.408$ & $(1.000)$ & $-1.200 \pm 1.181$ & $(-3.000)$ & $-2.200 \pm 0.327$ & $(-3.000)$ \\
\hline & $30 \mathrm{M}$ & $-0.800 \pm 0.742$ & $(-1.000)$ & $-0.400 \pm 0.618$ & $(-1.000)$ & $-1.000 \pm 0.471$ & $(-1.000)$ \\
\hline & $30 \mathrm{H}$ & $2.200 \pm 0.646$ & $(2.000)$ & $-1.400 \pm 0.542$ & $(-1.000)$ & $0.000 \pm 0.760$ & $(0.000)$ \\
\hline & $90 \mathrm{H}$ & $1.400 \pm 0.618$ & $(1.000)$ & $2.000 \pm 1.789$ & $(1.000)$ & $-2.800 \pm 1.555$ & $(-2.000)$ \\
\hline \multirow[t]{4}{*}{$R L$} & $30 \mathrm{~L}$ & $1.400 \pm 1.586$ & (3.000) & $-0.800 \pm 1.597$ & $(-4.000)$ & $0.200 \pm 1.541$ & $(1.000)$ \\
\hline & $30 \mathrm{M}$ & $-1.600 \pm 0.833$ & $(-1.000)$ & $-0.800 \pm 0.389$ & $(-1.000)$ & $-1.800 \pm 0.975$ & $(-1.000)$ \\
\hline & $30 \mathrm{H}$ & $0.400 \pm 0.400$ & $(1.000)$ & $-0.200 \pm 0.929$ & $(-1.000)$ & $-2.000 \pm 1.874$ & $(-2.000)$ \\
\hline & $90 \mathrm{H}$ & $-1.000 \pm 1.155$ & $(-2.000)$ & $3.000 \pm 1.414$ & $(2.000)$ & $2.000 \pm 0.869$ & $(1.000)$ \\
\hline \multirow[t]{4}{*}{ RSC } & $30 \mathrm{~L}$ & $0.000 \pm 1.054$ & $(1.000)$ & $-0.600 \pm 0.806$ & $(-1.000)$ & $-1.800 \pm 1.467$ & $(-1.000)$ \\
\hline & $30 \mathrm{M}$ & $-0.200 \pm 1.020$ & $(-1.000)$ & $1.000 \pm 2.055$ & $(-2.000)$ & $1.000 \pm 1.317$ & $(2.000)$ \\
\hline & $30 \mathrm{H}$ & $1.800 \pm 0.573$ & $(1.000)$ & $2.200 \pm 0.573$ & $(2.000)$ & $-1.000 \pm 0.816$ & $(-1.000)$ \\
\hline & $90 \mathrm{H}$ & $-1.200 \pm 1.569$ & $(-2.000)$ & $-0.800 \pm 0.975$ & $(-2.000)$ & $0.800 \pm 1.181$ & $(2.000)$ \\
\hline
\end{tabular}

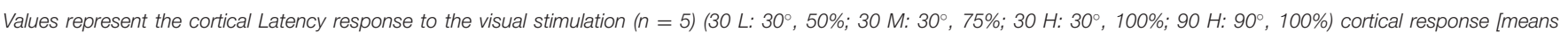

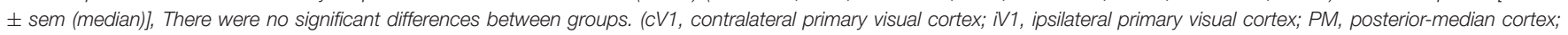

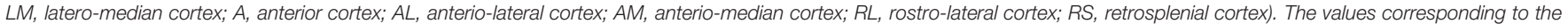
conditioned stimulus $(30 \mathrm{H})$ are underlined in gray.

strongly correlated with each other $(r=0.69-0.99)$, with the lowest correlation was expressed between the activation of $\mathrm{AL}$ and LM $(r=0.69)$ and the highest between $\mathrm{cV} 1$ and iV1 $(r$ $=0.99$ ). The correlation between $\mathrm{cVl}$ and the ventral visual stream (A, AM, AL, PM, RL) was stronger ( $r=0.84-0.98)$ than for the dorsal stream (LM; $r=0.70$ ). After the conditioning, the highest effect for the conditioned stimulus $(30 \mathrm{H})$ was seen in areas $\mathrm{AL}$ and RSC. In fact, a weaker correlation between both areas (and most of the cortical areas) was observed for this conditioned stimulus $(30 \mathrm{H})$ in the CS group. However, the correlation diminution was significant only between $\mathrm{AL}$ and A/RSC, and between RSC and AM. No substantial alteration was observed in response to the non-conditioned stimulus $(90 \mathrm{H})$. Interestingly, while using DPZ, this decorrelation between RSC and visual areas was not observable, except for in PM and RL. Despite the lack of significance, the correlation between LM and other areas was heavily diminished ( $r=-0.25$ vs. 0.60$)$. A similar but weaker decorrelation was also observed between AL, PM, 
TABLE 6 | Modification in the SNR ( $\triangle$ Post-Pre cortical response) in response of the visual stimulation.

\begin{tabular}{|c|c|c|c|c|c|c|c|}
\hline \multirow{3}{*}{$\begin{array}{l}\text { Area } \\
\mathrm{cV} 1\end{array}$} & \multirow{3}{*}{$\begin{array}{l}\text { Stim. } \\
30 \mathrm{~L}\end{array}$} & \multicolumn{6}{|c|}{ Treatment } \\
\hline & & \multicolumn{2}{|c|}{ Sham } & \multicolumn{2}{|l|}{ CS } & \multicolumn{2}{|c|}{ CS/DPZ } \\
\hline & & $-5.504 \pm 0.939$ & $(-6.355)$ & $-1.907 \pm 1.768$ & $(-3.996)$ & $-3.306 \pm 0.501$ & $(-5.837)$ \\
\hline & $30 \mathrm{M}$ & $-4.327 \pm 1.539$ & $(-4.141)$ & $-3.725 \pm 3.237$ & $(-2.985)$ & $-4.766 \pm 0.662$ & $(-11.005)$ \\
\hline & $30 \mathrm{H}$ & $-5.766 \pm 1.486$ & $(-8.209)$ & $2.983 \pm 2.863$ & $(-0.047)$ & $-9.187 \pm 1.766$ & $(-2.867)$ \\
\hline & $90 \mathrm{H}$ & $-2.594 \pm 0.959$ & $(-2.473)$ & $7.242 \pm 3.414$ & (3.423) & $-1.487 \pm 1.629$ & (0.603) \\
\hline \multirow[t]{4}{*}{ iV1 } & $30 \mathrm{~L}$ & $0.058 \pm 0.442$ & $(0.440)$ & $-0.854 \pm 0.508$ & $(-0.211)$ & $0.367 \pm 0.178$ & (0.085) \\
\hline & $30 \mathrm{M}$ & $-1.101 \pm 0.571$ & $(-0.779)$ & $0.340 \pm 0.628$ & $(1.567)$ & $0.295 \pm 0.430$ & $(-1.238)$ \\
\hline & $30 \mathrm{H}$ & $0.499 \pm 0.709$ & $(1.279)$ & $2.775 \pm 0.818$ & (2.652) & $-0.609 \pm 0.485$ & (0.623) \\
\hline & $90 \mathrm{H}$ & $-1.934 \pm 0.938$ & $(-2.564)$ & $2.819 \pm 0.750$ & $(2.850)$ & $1.653 \pm 0.981$ & $(-2.278)$ \\
\hline \multirow[t]{4}{*}{$\mathrm{AL}$} & $30 \mathrm{~L}$ & $-4.161 \pm 0.917$ & $(-3.268)$ & $-3.528 \pm 1.243$ & $(-3.304)$ & $-2.162 \pm 1.031$ & $(-2.411)$ \\
\hline & $30 \mathrm{M}$ & $-3.300 \pm 0.930$ & $(-3.170)$ & $-0.658 \pm 1.554$ & $(-1.325)$ & $-2.020 \pm 0.321$ & $(-4.938)$ \\
\hline & $30 \mathrm{H}$ & $-2.525 \pm 1.475$ & $(-2.129)$ & $0.056 \pm 1.580$ & $(-0.851)$ & $-5.234 \pm 0.403$ & $(-0.635)$ \\
\hline & $90 \mathrm{H}$ & $-3.407 \pm 1.386$ & $(-4.288)$ & $2.025 \pm 0.734$ & $(1.851)$ & $-0.655 \pm 1.501$ & $(0.031)$ \\
\hline \multirow[t]{4}{*}{$A$} & $30 \mathrm{~L}$ & $-0.144 \pm 1.189$ & $(-0.480)$ & $-2.874 \pm 0.800$ & $(-1.170)$ & $0.773 \pm 1.161$ & $(-0.308)$ \\
\hline & $30 \mathrm{M}$ & $-0.512 \pm 1.363$ & $(-0.520)$ & $-1.088 \pm 0.935$ & $(-0.018)$ & $-0.408 \pm 0.627$ & $(-1.397)$ \\
\hline & $30 \mathrm{H}$ & $2.965 \pm 0.779$ & (2.308) & $-0.354 \pm 0.667$ & $(-0.769)$ & $-1.519 \pm 0.226$ & $(0.332)$ \\
\hline & $90 \mathrm{H}$ & $1.111 \pm 1.156$ & $(0.113)$ & $4.870 \pm 1.985$ & $(2.017)$ & $1.008 \pm 1.144$ & $(-0.019)$ \\
\hline \multirow[t]{4}{*}{ AM } & $30 \mathrm{~L}$ & $0.185 \pm 1.218$ & $(-0.603)$ & $-1.956 \pm 1.227$ & $(-0.496)$ & $-0.877 \pm 1.074$ & $(-1.856)$ \\
\hline & $30 \mathrm{M}$ & $-0.361 \pm 1.240$ & $(-1.507)$ & $-0.606 \pm 1.568$ & $(-0.028)$ & $-2.107 \pm 0.452$ & $(-2.772)$ \\
\hline & $30 \mathrm{H}$ & $2.696 \pm 1.585$ & $(2.715)$ & $0.194 \pm 1.310$ & $(-1.336)$ & $-3.147 \pm 0.524$ & $(0.173)$ \\
\hline & $90 \mathrm{H}$ & $1.131 \pm 1.599$ & (1.388) & $4.603 \pm 1.724$ & (3.499) & $-0.831 \pm 1.035$ & $(-2.344)$ \\
\hline \multirow[t]{4}{*}{ PM } & $30 \mathrm{~L}$ & $-1.261 \pm 0.916$ & $(-2.382)$ & $-3.458 \pm 1.226$ & $(-5.494)$ & $-3.958 \pm 0.818$ & $(-3.910)$ \\
\hline & $30 \mathrm{M}$ & $-0.477 \pm 0.847$ & $(0.156)$ & $-3.034 \pm 1.772$ & $(-5.262)$ & $-4.272 \pm 0.556$ & $(-8.087)$ \\
\hline & $30 \mathrm{H}$ & $0.054 \pm 1.575$ & (2.053) & $0.177 \pm 1.799$ & $(-0.835)$ & $-6.313 \pm 1.139$ & $(-2.341)$ \\
\hline & $90 \mathrm{H}$ & $-0.384 \pm 1.063$ & $(-0.400)$ & $6.196 \pm 2.226$ & $(4.214)$ & $-0.942 \pm 1.939$ & $(-0.114)$ \\
\hline \multirow[t]{4}{*}{ LM } & $30 \mathrm{~L}$ & $-4.189 \pm 0.472$ & $(-4.626)$ & $-1.521 \pm 1.612$ & $(-1.382)$ & $0.095 \pm 0.730$ & $(-1.288)$ \\
\hline & $30 \mathrm{M}$ & $-3.416 \pm 1.276$ & $(-4.333)$ & $-0.116 \pm 2.088$ & $(0.060)$ & $-1.540 \pm 0.706$ & $(-6.654)$ \\
\hline & $30 \mathrm{H}$ & $-4.055 \pm 1.884$ & $(-6.771)$ & $2.858 \pm 2.120$ & $(0.285)$ & $-5.189 \pm 1.370$ & $(-0.990)$ \\
\hline & $90 \mathrm{H}$ & $-3.593 \pm 0.825$ & $(-5.035)$ & $7.007 \pm 3.201$ & $(0.956)$ & $1.232 \pm 1.013$ & $(-2.942)$ \\
\hline \multirow[t]{4}{*}{$R L$} & $30 \mathrm{~L}$ & $-1.623 \pm 1.146$ & $(-0.233)$ & $-3.190 \pm 0.893$ & $(-2.021)$ & $-1.334 \pm 1.462$ & $(-1.824)$ \\
\hline & $30 \mathrm{M}$ & $-2.034 \pm 1.059$ & $(-2.743)$ & $-1.453 \pm 1.530$ & $(-0.398)$ & $-1.982 \pm 0.200$ & $(-3.940)$ \\
\hline & $30 \mathrm{H}$ & $0.586 \pm 1.028$ & $(0.708)$ & $-1.045 \pm 1.074$ & $(-1.691)$ & $-4.368 \pm 0.332$ & (1.019) \\
\hline & $90 \mathrm{H}$ & $-1.250 \pm 1.559$ & $(-2.217)$ & $3.876 \pm 1.626$ & (2.352) & $-0.132 \pm 1.395$ & $(0.334)$ \\
\hline \multirow[t]{4}{*}{ RSC } & $30 \mathrm{~L}$ & $-0.883 \pm 0.622$ & $(0.254)$ & $-2.924 \pm 0.758$ & $(-2.125)$ & $0.274 \pm 0.566$ & $(-0.936)$ \\
\hline & $30 \mathrm{M}$ & $-1.326 \pm 0.450$ & $(-1.482)$ & $-0.712 \pm 0.956$ & $(-1.337)$ & $-0.043 \pm 0.423$ & $(-2.072)$ \\
\hline & $30 \mathrm{H}$ & $0.820 \pm 0.429$ & (1.683) & $-0.373 \pm 0.871$ & $(-1.383)$ & $-1.210 \pm 0.584$ & (0.513) \\
\hline & $90 \mathrm{H}$ & $-0.002 \pm 0.914$ & $(-0.129)$ & $2.018 \pm 0.884$ & $(1.010)$ & $0.285 \pm 0.594$ & $(-5.837)$ \\
\hline
\end{tabular}

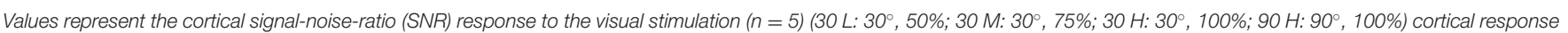

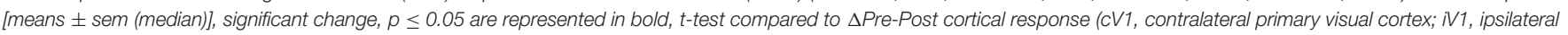

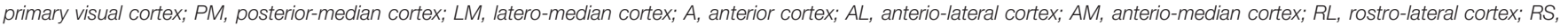
retrosplenial cortex). The values corresponding to the conditioned stimulus $(30 \mathrm{H})$ are underlined in gray.

$\mathrm{RL}$, and most of the cortical visual areas. However, the activation correlation was generally diminished in this group for the nonconditioned stimulus $(90 \mathrm{H})$, but those changes were discrete and not significant. Comparing the post-conditioning activation correlation of both conditioned groups (CS vs. CS/DPZ), there were changes in the correlation, but none were significant in response to each stimulus ( 30 and $90 \mathrm{H}$ ) (Figure 5). For the sham group, there were also rare isolated changes, i.e., the activation correlation for the $30 \mathrm{H}$ stimulus was significantly decreased between RSC and AM, and between $\mathrm{CV} 1$ and both iV1 and AM for the non-conditioned stimulus $(90 \mathrm{H})$.

\section{Resting State Correlations}

To evaluate the effect of conditioning on the resting state activity, which may reflect the long-term modification of the cortical network occurring in response to the conditioning, the change in the correlation between CaS was measured at rest. Our results showed that the monocular visual conditioning 


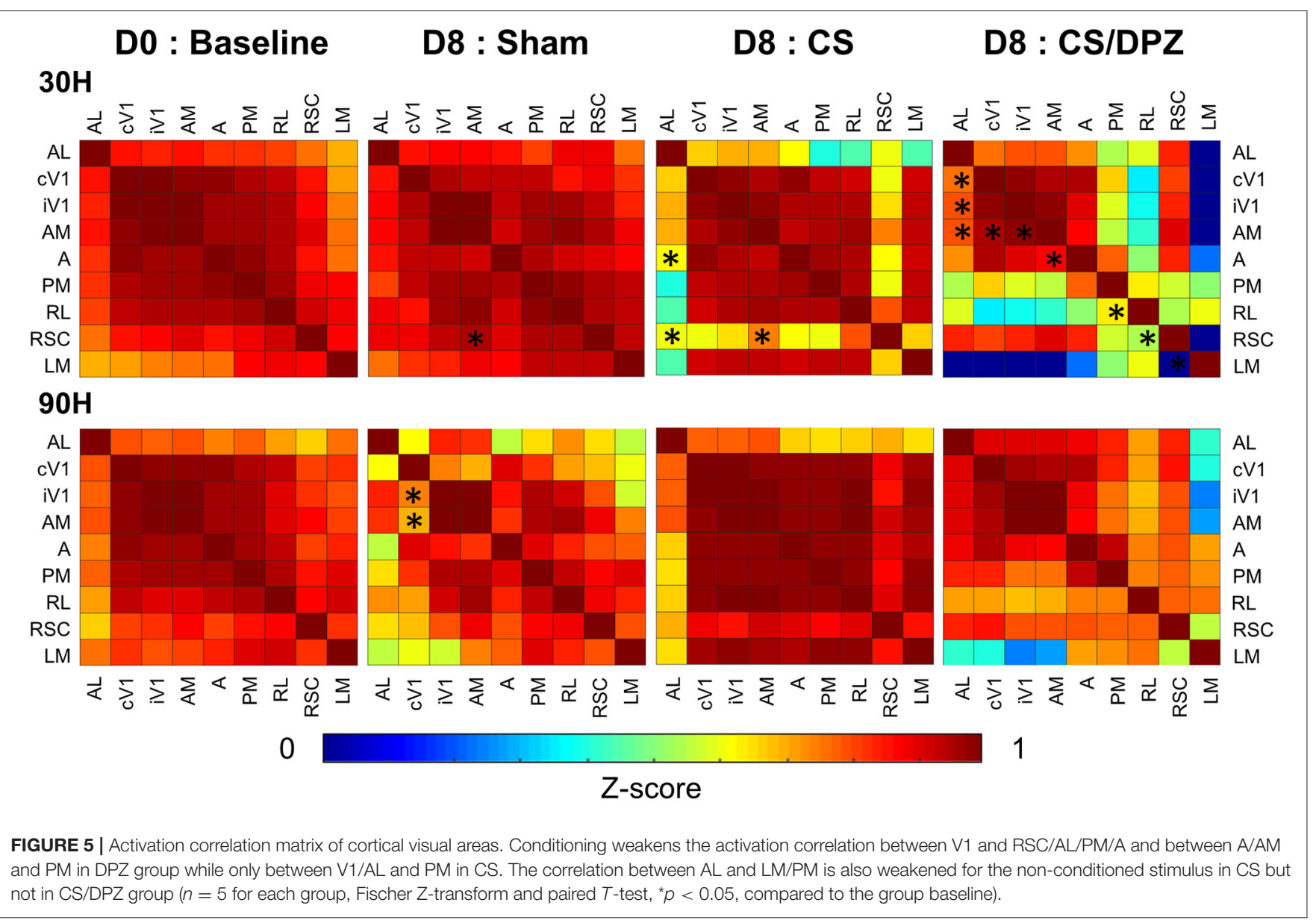

weakened the correlation between the binocular region of the ipsilateral V1 (iV1b) and $c V 1 m, c A, i V 1 m$, iLM, and iA. The cholinergic potentiation through DPZ injection during the conditioning partially restored the correlation between both hemispheres. We observed a diminution of the correlations only between $\mathrm{iV} 1 \mathrm{~b}$ and both $\mathrm{cA}$ and $\mathrm{iAC}$ in this group. While comparing the post-conditioning for both conditioned groups, a significant change in correlation between both hemispheres' $\mathrm{AL}, \mathrm{iV} 1 \mathrm{~b}$, and $\mathrm{cV} 1 \mathrm{~m}$, and between $\mathrm{cPM}$ and $\mathrm{cV} 1 \mathrm{~b}$ was observed. For the non-conditioned group, there was no major modification in the resting state correlation over the experiment period (Figure 6).

\section{Gene Expression Modification}

The expression of plasticity markers was quantified by RT-qPCR after our treatment. Our results showed that the conditioning enhanced the expression of $\mathrm{tPa}$ in $\mathrm{V} 1$ for both conditioned groups (CS group $=3.45 \pm 0.54, p=0.0001$; CS/DPZ group $=2.91 \pm 0.72, p=0.0005)$, but caused no modification in the expression of Lynx1, Lypd6, PSD95, and GAP43 compared to the non-conditioned group (Figure 7). While comparing both conditioned groups (CS vs. DPZ), no significant difference in
tPa expression was observed ( $p=0.6377)$, nor in any other gene's expression.

\section{DISCUSSION}

In this study, we examined the effects of a 7-day visual monocular conditioning on the mesoscopic map of the entire cortex, as well as cortical correlations with or without cholinergic potentiation via systemic DPZ administration $(0.3 \mathrm{mg} / \mathrm{kg})$. As the responses in other cortical areas were negligible, we centered our analysis on nine reactive cortical areas related to vision: A, AL, RL, AM, PM, LM, cV1, and iV1, as well as in the RSC. Our results showed that there was a neuronal activity decrease in the superficial layers after conditioning, enhanced by the DPZ treatment. The significant effects were located in the contralateral visual areas and in the RSC. The functional connectivity between visual areas also decreased following the conditioning potentiated by DPZ. However, those modifications were observed predominantly in the ventral visual pathway. Additionally, an upregulation of $\mathrm{tPa}$, a proteolytic factor involved in plasticity, was observed in the conditioned $\mathrm{V} 1$ regardless of the cholinergic potentiation, suggesting the involvement of synaptic plasticity in the conditioning process. 


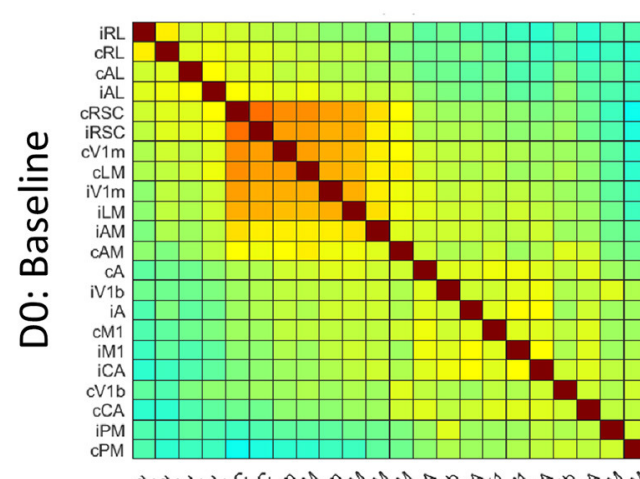

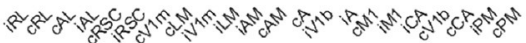

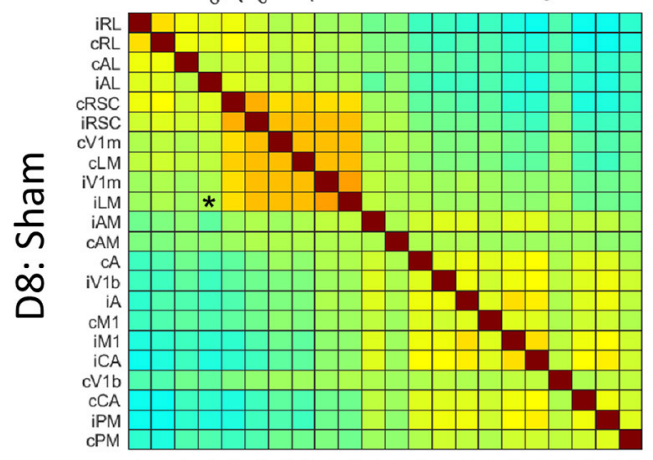

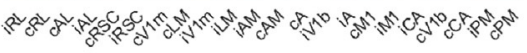
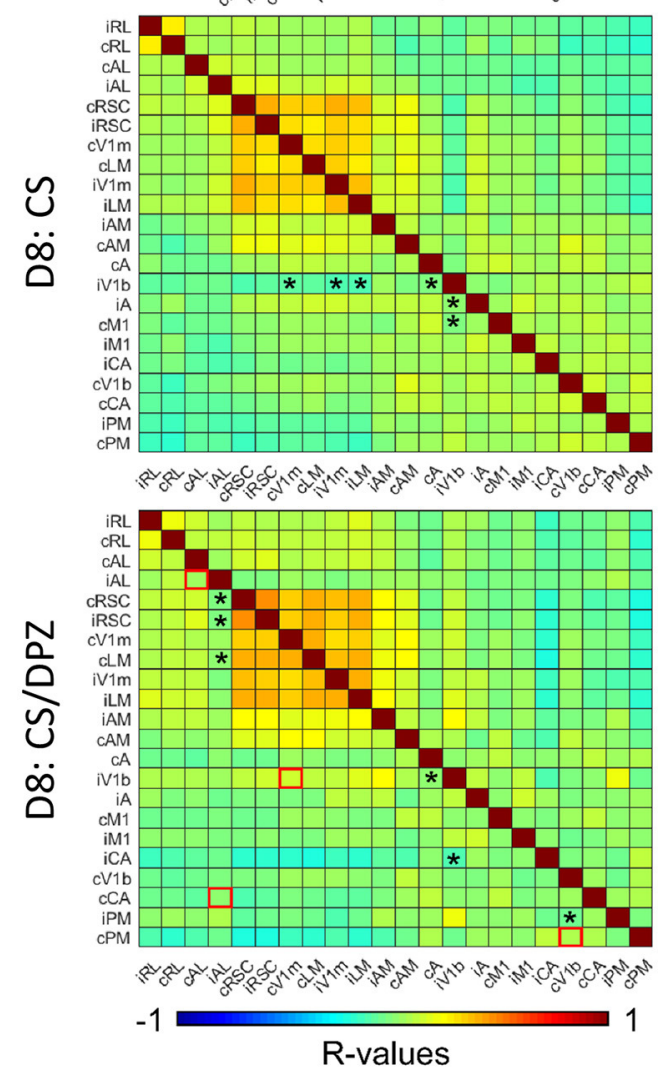

FIGURE 6 | Resting state correlation. Conditioning with saline weakens the correlation of ipsilateral binocular V1 (iV1b) with cV1M, cA, cM1, and IV1M.

(Continued)
FIGURE 6 | Injection of DPZ during the conditioning diminish this effect on $\mathrm{iV} 1 \mathrm{~b}$, while in DPZ group, only the correlation between $\mathrm{iV} 1 \mathrm{~b}$ and $\mathrm{CA}$ and cM1 are weakened $\left(n=5\right.$ for each group, Fischer $Z$-transform and paired $T$-test, ${ }^{*} p$ $<0.05$, compared to the baseline; unpaired $T$-test, red square $=p<0.05$, comparing D8 CS to D8 CS/DPZ resting state correlation).

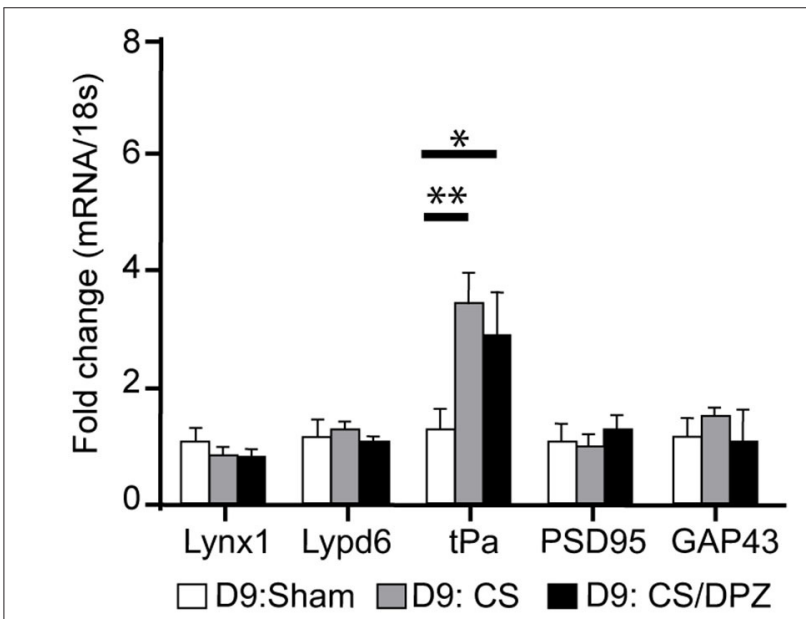

FIGURE 7 | Gene expression modification through conditioning. Conditioning enhanced the expression of tPa in both conditioned groups but caused no modification in the expression of Lynx1, Lypd6, mAChR M2, PSD95, and GAP43 ( $n=5$ for each group, multiple $t$-test, ${ }^{\star} p=0.004,{ }^{\star \star} p=0.0001$, compared to Sham group).

This is the first report showing mesoscale CaI mapping in the cortex upon visual stimulation with full field drifting gratings, and after a visual conditioning. The $\mathrm{CaS}$ was increased by a visual stimulation and was sensitive to the contrast but not the orientation of the gratings. The $\mathrm{CaS}$ was strikingly restricted to the cortical areas involved in vision. These areas were highly correlated during visual stimulation with drifting patterns in naive animals. However, the $\mathrm{CaS}$ was not increased by the visual stimulation of other areas, including the ipsilateral V1. The downstream neural transmission of $\mathrm{V} 1$ to the prefrontal cortex was thus not detectable in Thyl-GCaMP6s mice with these experimental conditions. In the resting state, the CaS was only slightly correlated between bilateral cortices, except in the case of the primary visual cortex. The main result shows a strong reduction in the $\mathrm{CaS}$ for the conditioned stimulus in most of the cortical areas after CS/DPZ treatment, although a slight tendency for a decreased signal was also seen with sham or CS conditions.

The decrease in cortical activity induced by CS/DPZ is surprising, as previous studies rather demonstrated an enhancement of visual-evoked activity in similar conditions (Cooke and Bear, 2010; Kang et al., 2014; Chamoun et al., 2016). First, this discrepancy might be explained by experimental considerations, i.e., the level of signal collection or arousal 
state of the animal. The mCaI technique using GP4.3 Thy1GCaMP6s mice is an amalgamation of the CaS from excitatory cell bodies, axons, and dendrites located in the superficial layers covering large areas of the cortex. On the other hand, previous electrophysiology recordings have been restricted to one site of layer 4 in V1 and result from the firing of both excitatory and inhibitory neurons. Moreover, recordings in the present study were performed on awake animals, as opposed to animals under anesthesia as seen in previous studies, which may change the neuronal activity, connectivity, or responsiveness to cholinergic input (Galuske et al., 2019). Specifically, awareness and the behavioral states of the animal such as arousal, attention, and locomotion (Niell and Stryker, 2010; Pakan et al., 2016) may influence the duration, dynamics of the evoked response, and cortico-cortical interactions (Sellers et al., 2015). It is possible, although we did not measure it, that repetitive administration of DPZ might slightly change the brain states of the animal although not detected in sleep duration for rats at this dose (Ishida and Kamei, 2009). Finally, mCaI measures the global rather than single-cell response. Due to the salt-and-pepper organization of the neurons in the rodent $\mathrm{V} 1$, it is possible that the $\mathrm{CaS}$ was augmented in conditioned and tuned neurons, but this signal could have been masked by the suppression of activity in the more numerous non-conditioned and un-tuned neurons by ACh, which suppresses irrelevant neuronal activation (CastroAlamancos and Oldford, 2002). The decrease of the fluorescent signal in superficial layers, rather than an enhancement in layer 4 neuronal activity, might also be explained by the functional organization of the visual cortex, particularly the layer-dependent neural activity. For example, a layer-specific response to visual stimulation and to cholinergic activation has been previously demonstrated (Obermayer et al., 2017; Yildirim et al., 2019). The excitatory effect of sensory input is stronger in layer 4 (Verdier and Dykes, 2001), which is explained by the endings of the thalamocortical fibers and by fewer GABAergic cells in this layer compared to layers $2 / 3$ (Gonchar et al., 2007). The activation of the layers $2 / 3$ depends on layer 4 feedforward input, layer 5 recurrent circuits, as well as layer 1 feedback from other cortical layers; this connectivity is orchestrated by the inhibition from GABAergic cells (Makino and Komiyama, 2015; D'souza et al., 2016). It is possible that, in our study, both conditioning groups (CS and DPZ-CS) showed inhibition of layer 2/3 pyramidal cells due to either this GABAergic drive or a top-down modulation. This is in line with the calcium activity diminution in layers $2 / 3$ after passive visual conditioning that has been previously observed (Makino and Komiyama, 2015; Henschke et al., 2020). It is also well-documented that cholinergic influence differs from one layer to another according to the receptors involved (Disney et al., 2012; Pfeffer et al., 2013; Obermayer et al., 2017), causing a differential effect of ACh (Oldford and Castro-Alamancos, 2003; Giocomo and Hasselmo, 2007; Soma et al., 2013b; Shimegi et al., 2016; Minces et al., 2017). In addition, it is possible that conditioning partially reduced cell firing, or a reduction of the $\mathrm{CaS}$ results from afferent axons, including projecting fibers in layer 1 (although the contribution of axons in the mesoscale $\mathrm{CaS}$ recorded is probably minor).
Our findings thus agree with previous studies showing that the conditioning might increase activation of GABAergic neurons in sensory cortices (Gierdalski et al., 2001; Jiao et al., 2006, 2011), leading to an upregulation of the inhibitory drive (Tokarski et al., 2007; Saar et al., 2012; Mckay et al., 2013). This inhibitory drive has been demonstrated as essential for the induction of condition-dependent synaptic plasticity and its maintenance (Posluszny et al., 2015). It is therefore possible that conditioning reduces the number of activated excitatory neurons in layers $2 / 3$ or their level of excitation, which would be exacerbated by ACh. Accordingly, ACh increases inhibitory drive and suppresses lateral spreading (Kimura and Baughman, 1997; Zinke et al., 2006; Obermayer et al., 2018). Furthermore, the spread of a $\mathrm{CaS}$ response to the visual stimulation (reduced size of activated area and restriction of the correlation to primary visual areas) was reduced only by CS/DPZ treatment, confirming previous results with ACh administration (Kimura et al., 1999; Silver et al., 2008). Our previous studies have also shown a strong dependency of cholinergic potentiation on M2-type muscarinic and nicotinic receptors (Kang et al., 2015) associated with GABAergic neurons (Disney and Aoki, 2008; Groleau et al., 2015). However, cholinergic fibers modulate various inhibitory circuits, i.e., feed-forward inhibition, lateral inhibition and disinhibition (Obermayer et al., 2018), so we cannot directly infer the effect on GABAergic circuits induced by enhanced cholinergic transmission from our experiment. On the other hand, a decreased response following conditioning might reflect an experience-dependent adaptation of neurons, in which the reduction of activity corresponds to an increase in neuronal efficiency, as the cortical response to visual stimulation is not affected in the upstream secondary cortical areas.

The CS/DPZ reduced the amplitude response to the conditioned stimulus in V1, AM, LM, AL, and RSC. The correlation of cortical areas that respond to the pattern stimulation was also affected by our treatment, but only in V1 and in the ventral pathway, while the dorsal path (represented by LM) remained unaffected. This is likely due to the visual stimulus used, i.e., drifting gratings, which are processed by the ventral pathway (Marshel et al., 2011; Smith et al., 2017). The greatest effects occur in V1 and PM, which is unsurprising considering the fact that neuron selectivity in V1 is essential to orientation and contrast changes (Glickfeld et al., 2013b) and because PM is one of the most innervated visual areas, along with LM and AL (Wang et al., 2012). The low temporal frequency of our stimuli $(1 \mathrm{~Hz})$ might explain why PM, which responds to low temporal but high spatial frequencies, expresses more modifications in its response post-conditioning than $\mathrm{AL}$, which has preferential affinity to high temporal and low spatial frequencies. These results might also suggest that the temporal frequency of the stimulation has a greater effect on the mouse's neuronal tuning than the spatial frequency. In fact, our stimulation (S.F.: 0.03 cpd, T.F.: $1 \mathrm{~Hz}$, sinusoidal grating) is closer to the preferred spatial frequency of AL (S.F.: $0.045 \mathrm{cpd}$ ) and the preferred temporal frequency of PM (T.F.: 1.2 Hz) (Andermann et al., 2011).

Aside from PM, the subsequent extrastriate visual area responses were not significantly affected, while $\mathrm{V} 1$ responses were 
reduced, suggesting an improved efficiency in V1 feedforward neurons projecting to those areas. The effect of the CS/DPZ did not seem to be related to the release of plasticity brakes Lynx1 and LypD6, which affects nicotinic transmission, since the expression of these molecules was not modified. The increased expression of $\mathrm{tPa}$ during CS, combined with a weakening of the conditioned-stimulus response, suggests the involvement of LTD and/or LTP mechanisms. In fact, this plasticity marker is well-known to be essential in experience-dependent plasticity (Mataga et al., 2004). Additionally, its expression is upregulated during long-term potentiation (Qian et al., 1993) and longterm depression (Calabresi et al., 2000). In contradistinction, the expression of GAP43, which has an influence on AMPA receptor endocytosis and LTD (Han et al., 2013), was not modified by any treatments. It is therefore possible that LTP was involved in the mechanism of conditioning, improving the efficiency of neurons in superficial layers. Despite our hypothesis, the effect of cholinergic potentiation does not seem to be related to the release of the plasticity brakes Lynx1 and LypD6, reducing nicotinic transmission, as the expression of these molecules were not modified. Knowing that the cholinergic system plays a key role in visual attentional processes (Herrero et al., 2008), the administration of DPZ might have contributed to an improved beneficial effect on visual transmission. Consequently, DPZ reduced the increased inter-individual variability in the CS groups, suggesting an attentional effect of increased levels of ACh.

DPZ also abolished the CS-induced decorrelation between interhemispheric binocular and monocular zones of V1 during resting state, suggesting an effect of ACh on binocular interaction. These results are also concomitant with a recent human study showing that DPZ administration reduces the ocular dominance shift normally observed after a monocular deprivation (Sheynin et al., 2019) and reduce interocular suppression (Sheynin et al., 2020). Knowing that the binocular response is influenced by multiple factors such as the thalamocortical input from both eyes, the GABAergic modulation, and the corticocortical projections, it might be further explained by the influence of ACh on each of these factors (Disney et al., 2012; Groleau et al., 2015; Vaucher et al., 2019). This result may reflect the modification in perceptual strength in the conditioned eye over the other in the binocular region as observed in a monocular deprivation experiment (Scholl et al., 2017).

In regard to present and previous results, we suggest that the global decrease observed in cortical calcium responses in the superficial layers of $\mathrm{V} 1$ and PM might be due to the attenuation of pyramidal neuron activation in layers $2 / 3$, even if layer 4 is activated, and thus reduces conscious perception of the conditioned stimulus. Accordingly, a similar repetitive passive visual stimulation causes a reduction of the calcium signals to the passive stimulation, whereas a rewarded presentation leads to an increased calcium response (Makino and Komiyama, 2015; Henschke et al., 2020). This may result from a suppression of the neurons' response to the passive conditioned stimulus in layers 2/3 from direct activation of the GABAergic neurons by feedforward inputs, or through top-down feedback activation of layer 1 inhibitory interneurons (Makino and Komiyama, 2015). It is also possible that the decreased activity resulted from reduced attention or motivation in the mice. It is tempting to speculate that this reduction of neuronal response in superficial layers probably reflects the habituation of the neurons to irrelevant stimuli, and prevents the upstream processing of this stimulus to high order cortices. Accordingly, we do not report any change in the high-level cortical areas. In that case, this suppression would diminish the perception of this signal, in line with previous studies suggesting the attenuation of the conscious perception of redundant signals that are irrelevant for survival (Briggs et al., 2013; Galuske et al., 2019). It is, however, contradictory to the effect of ACh in previous studies. First, ACh usually mediates visual attentional processes (Herrero et al., 2008; Li et al., 2018), therefore improving ACh cortical levels should alleviate the suppression effect of passive conditioning. $\mathrm{ACh}$ is usually considered as responsible for shifting the dynamics of the cortical circuits to a signal significant mode and enhancing cue detection (Sarter and Lustig, 2020). Second, the coupling of passive visual stimulation to electrical stimulation of cholinergic neurons or DPZ administration has been shown to selectively improve the detection of the conditioned grating after the training. This is in favor of an improved perception. In this regard, the effect of ACh on neuronal plasticity is highly relevant. First, the increase of tPA in this study suggests an LTP process, which is in line with previous studies showing the triggering of long-lasting events by ACh in V1 (Kang and Vaucher, 2009). Altogether, our results and these studies could argue for a processing of this passive stimulus for an automatic mode that does not require attentional demand and neuronal resources, but rather relies on improve neuronal efficiency. This would be in line with Furey and Ricciardi results proposing improved circuitry dynamics by DPZ in humans (Furey et al., 2000; Ricciardi et al., 2013).

\section{DATA AVAILABILITY STATEMENT}

The datasets generated for this study are available on request to the corresponding author.

\section{ETHICS STATEMENT}

The animal study was reviewed and approved by Comité de déontologie de l'expérimentation sur les animaux (CDEA) de l'université de Montréal.

\section{AUTHOR CONTRIBUTIONS}

GL performed the experiments, wrote the MATLAB script supervised by Labeo Technologies, analyzed the data, and wrote the first draft of the paper. RO contributed to RT-qPCR experiments. GL and EV designed the experiments, interpreted the results, and finalized writing. 
All authors contributed to the article and approved the submitted version.

\section{FUNDING}

This work was supported by a grant from the NSERC (RGPIN-2016-06634) to EV and from the FRQS Research Quebec Bio-Imaging Network (QBIN, Innovation Program) to $\mathrm{EV}$, in partnership with Labeo Technologies (Montreal,

\section{REFERENCES}

Andermann, M. L., Kerlin, A. M., Roumis, D. K., Glickfeld, L. L., and Reid, R. C. (2011). Functional specialization of mouse higher visual cortical areas. Neuron 72, 1025-1039. doi: 10.1016/j.neuron.2011.11.013

Bhattacharyya, A., Veit, J., Kretz, R., Bondar, I., and Rainer, G. (2013). Basal forebrain activation controls contrast sensitivity in primary visual cortex. BMC Neurosci. 14:55. doi: 10.1186/1471-2202-14-55

Bontempi, B., Whelan, K. T., Risbrough, V. B., Lloyd, G. K., and Menzaghi, F. (2003). Cognitive enhancing properties and tolerability of cholinergic agents in mice: a comparative study of nicotine, donepezil, and SIB-1553A, a subtypeselective ligand for nicotinic acetylcholine receptors. Neuropsychopharmacology 28, 1235-1246. doi: 10.1038/sj.npp.1300150

Bretin, S., Krazem, A., Henkous, N., Froger-Colleaux, C., Mocaer, E., Louis, C., et al. (2018). Synergistic enhancing-memory effect of donepezil and S 47445, an AMPA positive allosteric modulator, in middle-aged and aged mice. Psychopharmacology 235, 771-787. doi: 10.1007/s00213-017-4792-5

Briggs, F., Mangun, G. R., and Usrey, W. M. (2013). Attention enhances synaptic efficacy and the signal-to-noise ratio in neural circuits. Nature 499, 476-480. doi: 10.1038/nature12276

Calabresi, P., Napolitano, M., Centonze, D., Marfia, G. A., Gubellini, P., Teule, M. A., et al. (2000). Tissue plasminogen activator controls multiple forms of synaptic plasticity and memory. Eur. J. Neurosci. 12, 1002-1012. doi: 10.1046/j.1460-9568.2000.00991.x

Castro-Alamancos, M. A., and Oldford, E. (2002). Cortical sensory suppression during arousal is due to the activity-dependent depression of thalamocortical synapses. J. Physiol. 541, 319-331. doi: 10.1113/jphysiol.2002.016857

Chamoun, M., Groleau, M., Bhat, M., and Vaucher, E. (2016). Dose-dependent effect of donepezil administration on long-term enhancement of visually evoked potentials and cholinergic receptor overexpression in rat visual cortex. J. Physiol. Paris 110, 65-74. doi: 10.1016/j.jphysparis.2016.11.010

Chen, N., Sugihara, H., Sharma, J., Perea, G., Petravicz, J., Le, C., et al. (2012). Nucleus basalis-enabled stimulus-specific plasticity in the visual cortex is mediated by astrocytes. Proc. Natl. Acad. Sci. U.S.A. 109, E2832-E2841. doi: $10.1073 /$ pnas.1206557109

Chen, N., Sugihara, H., and Sur, M. (2015). An acetylcholine-activated microcircuit drives temporal dynamics of cortical activity. Nat. Neurosci. 18, 892-902. doi: $10.1038 / \mathrm{nn} .4002$

Chen, T. W., Wardill, T. J., Sun, Y., Pulver, S. R., Renninger, S. L., Baohan, A., et al. (2013). Ultrasensitive fluorescent proteins for imaging neuronal activity. Nature 499, 295-300. doi: 10.1038/nature12354

Chen, X., Hoffmann, K. P., Albright, T. D., and Thiele, A. (2012). Effect of featureselective attention on neuronal responses in macaque area MT. J. Neurophysiol. 107, 1530-1543. doi: 10.1152/jn.01042.2010

Chubykin, A. A., Roach, E. B., Bear, M. F., and Shuler, M. G. (2013). A cholinergic mechanism for reward timing within primary visual cortex. Neuron 77, 723-735. doi: 10.1016/j.neuron.2012.12.039

Cooke, S. F., and Bear, M. F. (2010). Visual experience induces long-term potentiation in the primary visual cortex. J. Neurosci. 30, 16304-16313. doi: 10.1523/JNEUROSCI.4333-10.2010

Coppola, J. J., Ward, N. J., Jadi, M. P., and Disney, A. A. (2016). Modulatory compartments in cortex and local regulation of cholinergic tone. J. Physiol. Paris 110, 3-9. doi: 10.1016/j.jphysparis.2016.08.001
QC, Canada). GL was the recipient of a scholarship from the QBIN and from the École d'Optométrie of Université de Montréal.

\section{ACKNOWLEDGMENTS}

The authors are grateful to Drs. Matthieu Vanni (School of Optometry) and Samuel Bélanger (Labeo Technologies Inc.) for their valuable assistance in mesoscopic calcium imaging, including in the development of the scripts for the analysis.

Dana, H., Chen, T. W., Hu, A., Shields, B. C., Guo, C., Looger, L. L., et al. (2014). Thy1-GCaMP6 transgenic mice for neuronal population imaging in vivo. PLoS ONE 9:e108697. doi: 10.1371/journal.pone.0108697

Darvas, M., Morsch, M., Racz, I., Ahmadi, S., Swandulla, D., and Zimmer, A. (2009). Modulation of the $\mathrm{Ca}^{2+}$ conductance of nicotinic acetylcholine receptors by Lypd6. Eur. Neuropsychopharmacol. 19, 670-681. doi: 10.1016/j.euroneuro.2009.03.007

Demars, M. P., and Morishita, H. (2014). Cortical parvalbumin and somatostatin GABA neurons express distinct endogenous modulators of nicotinic acetylcholine receptors. Mol. Brain 7:75. doi: 10.1186/s13041-014-0075-9

Disney, A. A., and Aoki, C. (2008). Muscarinic acetylcholine receptors in macaque V1 are most frequently expressed by parvalbumin-immunoreactive neurons. $J$. Comp. Neurol. 507, 1748-1762. doi: 10.1002/cne.21616

Disney, A. A., Aoki, C., and Hawken, M. J. (2012). Cholinergic suppression of visual responses in primate $\mathrm{V} 1$ is mediated by GABAergic inhibition. J. Neurophysiol. 108, 1907-1923. doi: 10.1152/jn.001 88.2012

D'souza, R. D., Meier, A. M., Bista, P., Wang, Q., and Burkhalter, A. (2016). Recruitment of inhibition and excitation across mouse visual cortex depends on the hierarchy of interconnecting areas. Elife 5:e19332. doi: 10.7554/eLife.19332.018

Furey, M. L., Pietrini, P., and Haxby, J. V. (2000). Cholinergic enhancement and increased selectivity of perceptual processing during working memory. Science 290, 2315-2319. doi: 10.1126/science.290.5500.2315

Galuske, R. A. W., Munk, M. H. J., and Singer, W. (2019). Relation between gamma oscillations and neuronal plasticity in the visual cortex. Proc. Natl. Acad. Sci. U.S.A. 116, 23317-23325. doi: 10.1073/pnas.1901277116

Gavornik, J. P., and Bear, M. F. (2014). Learned spatiotemporal sequence recognition and prediction in primary visual cortex. Nat. Neurosci. 17, 732-737. doi: 10.1038/nn.3683

Gaykema, R. P., Luiten, P. G., Nyakas, C., Traber, J. (1990). Cortical projection patterns of the medial septum-diagonal band complex. J. Comp. Neurol. 293, 103-124. doi: 10.1002/cne.902930109

Geerts, H., Guillaumat, P.-O., Grantham, C., Bode, W., Anciaux, K., and Sachak, S. (2005). Brain levels and acetylcholinesterase inhibition with galantamine and donepezil in rats, mice, and rabbits. Brain Res. 1033, 186-193. doi: 10.1016/j.brainres.2004.11.042

Gias, C., Hewson-Stoate, N., Jones, M., Johnston, D., Mayhew, J. E., and Coffey, P. J. (2005). Retinotopy within rat primary visual cortex using optical imaging. Neuroimage 24, 200-206. doi: 10.1016/j.neuroimage.2004.08.015

Gierdalski, M., Jablonska, B., Siucinska, E., Lech, M., Skibinska, A., and Kossut, M. (2001). Rapid regulation of GAD67 mRNA and protein level in cortical neurons after sensory learning. Cereb. Cortex 11, 806-815. doi: 10.1093/cercor/11.9.806

Giocomo, L. M., and Hasselmo, M. E. (2007). Neuromodulation by glutamate and acetylcholine can change circuit dynamics by regulating the relative influence of afferent input and excitatory feedback. Mol. Neurobiol. 36, 184-200. doi: 10.1007/s12035-007-0032-z

Glickfeld, L. L., Andermann, M. L., Bonin, V., and Reid, R. C. (2013a). Corticocortical projections in mouse visual cortex are functionally target specific. Nat. Neurosci. 16, 219-226. doi: 10.1038/nn.3300

Glickfeld, L. L., Histed, M. H., and Maunsell, J. H. (2013b). Mouse primary visual cortex is used to detect both orientation and contrast changes. J. Neurosci. 33, 19416-19422. doi: 10.1523/JNEUROSCI.3560-13.2013 
Glickfeld, L. L., and Olsen, S. R. (2017). Higher-order areas of the mouse visual cortex. Аnnu. Rev. Vis. Sci. 3, 251-273. doi: 10.1146/annurev-vision-102016-061331

Gonchar, Y., Wang, Q., and Burkhalter, A. (2007). Multiple distinct subtypes of GABAergic neurons in mouse visual cortex identified by triple immunostaining. Front. Neuroanat. 1:3. doi: 10.3389/neuro.05.00 3.2007

Groleau, M., Kang, J. I., Huppe-Gourgues, F., and Vaucher, E. (2015). Distribution and effects of the muscarinic receptor subtypes in the primary visual cortex. Front. Synaptic Neurosci. 7:10. doi: 10.3389/fnsyn.2015.00010

Groleau, M., Nguyen, H. N., Vanni, M. P., Huppe-Gourgues, F., Casanova, C., and Vaucher, E. (2014). Impaired functional organization in the visual cortex of muscarinic receptor knock-out mice. Neuroimage 98, 233-242. doi: 10.1016/j.neuroimage.2014.05.016

Guevara, E., Sadekova, N., Girouard, H., and Lesage, F. (2013). Optical imaging of resting-state functional connectivity in a novel arterial stiffness model. Biomed. Opt. Express 4, 2332-2346. doi: 10.1364/BOE.4.002332

Han, M.-H., Jiao, S., Jia, J.-M., Chen, Y., Chen, C. Y., Gucek, M., et al. (2013). The novel caspase-3 substrate Gap43 is involved in AMPA receptor endocytosis and long-term depression. Mol. Cell. Proteomics 12, 3719-3731. doi: 10.1074/mcp.M113.030676

Hendel, T., Mank, M., Schnell, B., Griesbeck, O., Borst, A., and Reiff, D. F. (2008). Fluorescence changes of genetic calcium indicators and OGB- 1 correlated with neural activity and calcium in vivo and in vitro. J. Neurosci. 28, 7399-7411. doi: 10.1523/JNEUROSCI.1038-08.2008

Hensch, T. K. (2005). Critical period plasticity in local cortical circuits. Nat. Rev. Neurosci. 6, 877-888. doi: 10.1038/nrn1787

Henschke, J. U., Dylda, E., Katsanevaki, D., Dupuy, N., Currie, S. P., Amvrosiadis, T., et al. (2020). Reward association enhances stimulus-specific representations in primary visual cortex. Curr. Biol. 30, 1-15. doi: 10.1016/j.cub.2020. 03.018

Herrero, J. L., Roberts, M. J., Delicato, L. S., Gieselmann, M. A., Dayan, P., and Thiele, A. (2008). Acetylcholine contributes through muscarinic receptors to attentional modulation in V1. Nature 454, 1110-1114. doi: $10.1038 /$ nature 07141

Huberman, A. D., and Niell, C. M. (2011). What can mice tell us about how vision works? Trends Neurosci. 34, 464-473. doi: 10.1016/j.tins.2011.07.002

Huppé-Gourgues, F., Jegouic, K., Vaucher, E., (2018). Topographic organization of cholinergic innervation from the basal forebrain to the visual cortex in the rat. Front. Neural Circuits. 12:19. doi: 10.3389/fncir.2018.00019

Ishida, T., and Kamei, C. (2009). Characteristic effects of anti-dementia drugs on rat sleep patterns. J. Pharmacol. Sci. 109, 449-455. doi: 10.1254/jphs.08229FP

Jiao, Y., Zhang, C., Yanagawa, Y., and Sun, Q.-Q. (2006). Major effects of sensory experiences on the neocortical inhibitory circuits. J. Neurosci. 26, 8691-8701. doi: 10.1523/JNEUROSCI.2478-06.2006

Jiao, Y., Zhang, Z., Zhang, C., Wang, X., Sakata, K., Lu, B., et al. (2011). A key mechanism underlying sensory experience-dependent maturation of neocortical GABAergic circuits in vivo. Proc. Natl. Acad. Sci. U.S.A. 108, 12131-12136. doi: 10.1073/pnas.1105296108

Kang, J. I., Groleau, M., Dotigny, F., Giguere, H., and Vaucher, E. (2014). Visual training paired with electrical stimulation of the basal forebrain improves orientation-selective visual acuity in the rat. Brain Struct. Funct. 219, 1493-1507. doi: 10.1007/s00429-013-0582-y

Kang, J. I., Huppe-Gourgues, F., and Vaucher, E. (2015). Pharmacological mechanisms of cortical enhancement induced by the repetitive pairing of visual/cholinergic stimulation. PLoS ONE 10:e0141663. doi: 10.1371 /journal.pone. 0141663

Kang, J. I., and Vaucher, E. (2009). Cholinergic pairing with visual activation results in long-term enhancement of visual evoked potentials. PLoS ONE 4:e5995. doi: 10.1371/journal.pone.0005995

Kilgard, M. P., and Merzenich, M. M. (1998). Cortical map reorganization enabled by nucleus basalis activity. Science 279, 1714-1718. doi: $10.1126 /$ science.279.5357.1714

Kim, E., and Sheng, M. (2004). PDZ domain proteins of synapses. Nat. Rev. Neurosci. 5, 771-781. doi: 10.1038/nrn1517

Kimura, F., and Baughman, R. W. (1997). Distinct muscarinic receptor subtypes suppress excitatory and inhibitory synaptic responses in cortical neurons. $J$. Neurophysiol. 77, 709-716. doi: 10.1152/jn.1997.77.2.709
Kimura, F., Fukuda, M., and Tsumoto, T. (1999). Acetylcholine suppresses the spread of excitation in the visual cortex revealed by optical recording: possible differential effect depending on the source of input. Eur. J. Neurosci. 11, 3597-3609. doi: 10.1046/j.1460-9568.1999.00779.x

Leaderbrand, K., Chen, H. J., Corcoran, K. A., Guedea, A. L., Jovasevic, V., Wess, J., et al. (2016). Muscarinic acetylcholine receptors act in synergy to facilitate learning and memory. Learn. Memory 23, 631-638. doi: 10.1101/lm.043133.116

Li, X., Yu, B., Sun, Q., Zhang, Y., Ren, M., Zhang, X., et al. (2018). Generation of a whole-brain atlas for the cholinergic system and mesoscopic projectome analysis of basal forebrain cholinergic neurons. Proc. Natl. Acad. Sci. U.S.A. 115, 415-420. doi: 10.1073/pnas.1703601115

Livak, K. J., and Schmittgen, T. D. (2001). Analysis of relative gene expression data using real-time quantitative PCR and the 2(-Delta Delta $\mathrm{C}(\mathrm{T})$ ) method. Methods 25, 402-408. doi: 10.1006/meth.2001.1262

Ma, Y., Shaik, M. A., Kim, S. H., Kozberg, M. G., Thibodeaux, D. N., Zhao, H. T., et al. (2016). Wide-field optical mapping of neural activity and brain haemodynamics: considerations and novel approaches. Philos. Trans. R. Soc. Lond. B Biol. Sci. 371:20150360. doi: 10.1098/rstb.2015.0360

Makino, H., and Komiyama, T. (2015). Learning enhances the relative impact of top-down processing in the visual cortex. Nat. Neurosci. 18, 1116-1122. doi: $10.1038 / \mathrm{nn} .4061$

Marshel, J. H., Garrett, M. E., Nauhaus, I., and Callaway, E. M. (2011). Functional specialization of seven mouse visual cortical areas. Neuron 72, 1040-1054. doi: 10.1016/j.neuron.2011.12.004

Mataga, N., Mizuguchi, Y., and Hensch, T. K. (2004). Experience-dependent pruning of dendritic spines in visual cortex by tissue plasminogen activator. Neuron 44, 1031-1041. doi: 10.1016/j.neuron.2004.11.028

Mataga, N., Nagai, N., and Hensch, T. K. (2002). Permissive proteolytic activity for visual cortical plasticity. Proc. Natl. Acad. Sci. U.S.A. 99, 7717-7721. doi: 10.1073/pnas.102088899

Mcclure-Begley, T. D., King, N. M., Collins, A. C., Stitzel, J. A., Wehner, J. M., and Butt, C. M. (2009). Acetylcholine-stimulated [3H]GABA release from mouse brain synaptosomes is modulated by alpha4beta2 and alpha4alpha5beta2 nicotinic receptor subtypes. Mol. Pharmacol. 75, 918-926. doi: 10.1124/mol.108.052274

Mckay, B. M., Oh, M. M., and Disterhoft, J. F. (2013). Learning increases intrinsic excitability of hippocampal interneurons. J. Neurosci. 33, 5499-5506. doi: 10.1523/JNEUROSCI.4068-12.2013

Mentis, M. J., Sunderland, T., Lai, J., Connolly, C., Krasuski, J., Levine, B., et al. (2001). Muscarinic versus nicotinic modulation of a visual task. a pet study using drug probes. Neuropsychopharmacology 25, 555-564. doi: 10.1016/S0893-133X(01)00264-0

Minces, V., Pinto, L., Dan, Y., and Chiba, A. A. (2017). Cholinergic shaping of neural correlations. Proc. Natl. Acad. Sci. U.S.A. 114, 5725-5730. doi: $10.1073 /$ pnas. 1621493114

Mishkin, M., Lewis, M. E., and Ungerleider, L. G. (1982). Equivalence of parietopreoccipital subareas for visuospatial ability in monkeys. Behav. Brain Res. 6, 41-55. doi: 10.1016/0166-4328(82)90080-8

Morishita, H., Miwa, J. M., Heintz, N., and Hensch, T. K. (2010). Lynx1, a cholinergic brake, limits plasticity in adult visual cortex. Science 330, 1238-1240. doi: 10.1126/science. 1195320

Motulsky, H. J., and Brown, R. E. (2006). Detecting outliers when fitting data with nonlinear regression - a new method based on robust nonlinear regression and the false discovery rate. BMC Bioinformatics 7:123. doi: 10.1186/1471-2105-7-123

Niell, C. M., and Stryker, M. P. (2010). Modulation of visual responses by behavioral state in mouse visual cortex. Neuron 65, 472-479. doi: 10.1016/j.neuron.2010.01.033

Obermayer, J., Heistek, T. S., Kerkhofs, A., Goriounova, N. A., Kroon, T., Baayen, J. C., et al. (2018). Lateral inhibition by Martinotti interneurons is facilitated by cholinergic inputs in human and mouse neocortex. Nat. Commun. 9:4101. doi: 10.1038/s41467-018-06628-w

Obermayer, J., Verhoog, M. B., Luchicchi, A., and Mansvelder, H. D. (2017). Cholinergic modulation of cortical microcircuits is layer-specific: evidence from rodent, monkey and human brain. Front. Neural Circuits 11:100. doi: $10.3389 /$ fncir.2017.00100

Oldford, E., and Castro-Alamancos, M. (2003). Input-specific effects of acetylcholine on sensory and intracortical evoked responses 
in the "barrel cortex" in vivo. Neuroscience 117, 769-778. doi: 10.1016/S0306-4522(02)00663-2

Pakan, J. M. P., Lowe, S. C., Dylda, E., Keemink, S. W., Currie, S. P., Coutts, C. A., et al. (2016). Behavioral-state modulation of inhibition is contextdependent and cell type specific in mouse visual cortex. Elife 5:e14985. doi: 10.7554/eLife.14985.013

Pfeffer, C. K., Xue, M., He, M., Huang, Z. J., and Scanziani, M. (2013). Inhibition of inhibition in visual cortex: the logic of connections between molecularly distinct interneurons. Nat. Neurosci. 16, 1068-1076. doi: 10.1038/nn.3446

Posluszny, A., Liguz-Lecznar, M., Turzynska, D., Zakrzewska, R., Bielecki, M., and Kossut, M. (2015). Learning-dependent plasticity of the barrel cortex is impaired by restricting GABA-ergic transmission. PLOS ONE 10:e0144415. doi: 10.1371/journal.pone.0144415

Qian, Z., Gilbert, M. E., Colicos, M. A., Kandel, E. R., and Kuhl, D. (1993). Tissue-plasminogen activator is induced as an immediate-early gene during seizure, kindling and long-term potentiation. Nature 361, 453-457. doi: $10.1038 / 361453 \mathrm{a} 0$

Ricciardi, E., Handjaras, G., Bernardi, G., Pietrini, P., and Furey, M. L. (2013). Cholinergic enhancement reduces functional connectivity and BOLD variability in visual extrastriate cortex during selective attention. Neuropharmacology 64, 305-313. doi: 10.1016/j.neuropharm.2012.07.003

Rieke, F., Warland, D., Steveninck, R. D. R. V., and Bialek, W. (1999). Spikes: Exploring the Neural Code. Cambridge, MA; MIT Press.

Rokem, A., and Silver, M. A. (2013). The benefits of cholinergic enhancement during perceptual learning are long-lasting. Front. Comput. Neurosci. 7:66. doi: $10.3389 /$ fncom.2013.00066

Rothman, K. J. (1990). No adjustments are needed for multiple comparisons. Epidemiology 1, 43-46. doi: 10.1097/00001648-199001000-00010

Saar, D., Reuveni, I., and Barkai, E. (2012). Mechanisms underlying rule learninginduced enhancement of excitatory and inhibitory synaptic transmission. $J$. Neurophysiol. 107, 1222-1229. doi: 10.1152/jn.00356.2011

Sadahiro, M., Sajo, M., and Morishita, H. (2016). Nicotinic regulation of experience-dependent plasticity in visual cortex. J. Physiol. Paris 110, 29-36. doi: 10.1016/j.jphysparis.2016.11.003

Sarter, M., and Lustig, C. (2020). Forebrain cholinergic signaling: wired and phasic, not tonic, and causing behavior. J. Neurosci. 40, 712-719. doi: 10.1523/JNEUROSCI.1305-19.2019

Scholl, B., Pattadkal, J. J., and Priebe, N. J. (2017). Binocular disparity selectivity weakened after monocular deprivation in mouse V1. J. Neurosci. 37, 6517-6526. doi: 10.1523/JNEUROSCI.1193-16.2017

Sellers, K. K., Bennett, D. V., Hutt, A., Williams, J. H., and Fröhlich, F. (2015). Awake vs. anesthetized: layer-specific sensory processing in visual cortex and functional connectivity between cortical areas. J. Neurophysiol. 113, 3798-3815. doi: $10.1152 /$ jn.00923.2014

Sheynin, Y., Chamoun, M., Baldwin, A. S., Rosa-Neto, P., Hess, R. F., and Vaucher, E. (2019). Cholinergic potentiation alters perceptual eye dominance plasticity induced by a few hours of monocular patching in adults. Front. Neurosci. 13:22. doi: $10.3389 /$ fnins.2019.00022

Sheynin, Y., Rosa-Neto, P., Hess, R. F., and Vaucher, E. (2020). Cholinergic modulation of binocular vision. J. Neurosci. doi: 10.1523/JNEUROSCI.2484-19.2020

Shimegi, S., Kimura, A., Sato, A., Aoyama, C., Mizuyama, R., Tsunoda, K., et al. (2016). Cholinergic and serotonergic modulation of visual information processing in monkey V1. J. Physiol. Paris 110, 44-51. doi: 10.1016/j.jphysparis.2016.09.001

Silver, M. A., Shenhav, A., and D'esposito, M. (2008). Cholinergic enhancement reduces spatial spread of visual responses in human early visual cortex. Neuron 60, 904-914. doi: 10.1016/j.neuron.2008.09.038

Smith, I. T., Townsend, L. B., Huh, R., Zhu, H., and Smith, S. L. (2017). Streamdependent development of higher visual cortical areas. Nat. Neurosci. 20, 200-208. doi: 10.1038/nn.4469

Soma, S., Shimegi, S., Osaki, H., and Sato, H. (2012). Cholinergic modulation of response gain in the primary visual cortex of the macaque. J. Neurophysiol. 107, 283-291. doi: 10.1152/jn.00330.2011
Soma, S., Shimegi, S., Suematsu, N., and Sato, H. (2013a). Cholinergic modulation of response gain in the rat primary visual cortex. Sci. Rep. 3:1138. doi: $10.1038 /$ srep01138

Soma, S., Shimegi, S., Suematsu, N., Tamura, H., and Sato, H. (2013b). Modulation-specific and laminar-dependent effects of acetylcholine on visual responses in the rat primary visual cortex. PLoS ONE 8:e68430. doi: 10.1371/journal.pone.0068430

Soma, S., Suematsu, N., and Shimegi, S. (2013c). Cholinesterase inhibitor, donepezil, improves visual contrast detectability in freely behaving rats. Behav. Brain Res. 256, 362-367. doi: 10.1016/j.bbr.2013.08.022

Tokarski, K., Urban-Ciecko, J., Kossut, M., and Hess, G. (2007). Sensory learning-induced enhancement of inhibitory synaptic transmission in the barrel cortex of the mouse. Eur. J. Neurosci. 26, 134-141. doi: $10.1111 /$ j.1460-9568.2007.05629.x

Turchi, J., and Sarter, M. (1997). Cortical acetylcholine and processing capacity: effects of cortical cholinergic deafferentation on crossmodal divided attention in rats. Brain Res. Cogn. Brain Res. 6, 147-158. doi: 10.1016/S0926-6410(97)00027-X

Vaucher, E., Laliberte, G., Higgins, M. C., Maheux, M., Jolicoeur, P., and Chamoun, M. (2019). Cholinergic potentiation of visual perception and vision restoration in rodents and humans. Restor. Neurol. Neurosci. 37, 553-569. doi: 10.3233/RNN-190947

Verdier, D., and Dykes, R. W. (2001). Long-term cholinergic enhancement of evoked potentials in rat hindlimb somatosensory cortex displays characteristics of long-term potentiation. Exp. Brain Res. 137, 71-82. doi: $10.1007 / \mathrm{s} 002210000646$

Voss, P., Thomas, M., Chou, Y. C., Cisneros-Franco, J. M., Ouellet, L., and De Villers-Sidani, E. (2016). Pairing cholinergic enhancement with perceptual training promotes recovery of age-related changes in rat primary auditory cortex. Neural. Plast. 2016:1801979. doi: 10.1155/2016/ 1801979

Wang, Q., and Burkhalter, A. (2007). Area map of mouse visual cortex. J. Comp. Neurol. 502, 339-357. doi: 10.1002/cne.21286

Wang, Q., Sporns, O., and Burkhalter, A. (2012). Network analysis of corticocortical connections reveals ventral and dorsal processing streams in mouse visual cortex. J. Neurosci. 32, 4386-4399. doi: 10.1523/JNEUROSCI.6063-11.2012

Wekselblatt, J. B., Flister, E. D., Piscopo, D. M., and Niell, C. M. (2016). Large-scale imaging of cortical dynamics during sensory perception and behavior. J. Neurophysiol. 115, 2852-2866. doi: 10.1152/jn.01056. 2015

Yildirim, M., Sugihara, H., So, P. T. C., and Sur, M. (2019). Functional imaging of visual cortical layers and subplate in awake mice with optimized three-photon microscopy. Nat. Commun. 10:177. doi: 10.1038/s41467-01808179-6

Zhuang, J., Ng, L., Williams, D., Valley, M., Li, Y., Garrett, M., et al. (2017). An extended retinotopic map of mouse cortex. Elife 6:e18372. doi: 10.7554/eLife.18372

Zinke, W., Roberts, M. J., Guo, K., Mcdonald, J. S., Robertson, R., and Thiele, A. (2006). Cholinergic modulation of response properties and orientation tuning of neurons in primary visual cortex of anaesthetized Marmoset monkeys. Eur. J. Neurosci. 24, 314-328. doi: 10.1111/j.1460-9568.2006.04882.x

Conflict of Interest: The authors declare that the research was conducted in the absence of any commercial or financial relationships that could be construed as a potential conflict of interest.

Copyright (๑) 2020 Laliberté, Othman and Vaucher. This is an open-access article distributed under the terms of the Creative Commons Attribution License (CC BY). The use, distribution or reproduction in other forums is permitted, provided the original author(s) and the copyright owner(s) are credited and that the original publication in this journal is cited, in accordance with accepted academic practice. No use, distribution or reproduction is permitted which does not comply with these terms. 